\title{
The Role of Atmospheric Elements in the Wide Band-Gap Semiconductors
}

\author{
R. JAKIEEA* \\ Institute of Physics, Polish Academy of Sciences, Aleja Lotnikow 32/46, PL-02668 Warsaw, Poland \\ (Received June 4, 2019; revised version August 14, 2019; in final form August 22, 2019)
}

\begin{abstract}
The paper addresses the role of ambient elements ( $\mathrm{H}, \mathrm{C}, \mathrm{N}$ and $\mathrm{O}$ ) in the wide-bandgap semiconductor compounds. Their prevalence in the atmosphere imposes limitations not only on the purity of the materials under processing but, also, on the detection and measurement of the content of these species. Specifically, a review of electrical and optical properties, based on the available literature, is presented for: hydrogen in $\mathrm{GaN}, \mathrm{ZnO}$ and $\mathrm{SiC}$, carbon in $\mathrm{GaN}$ and $\mathrm{ZnO}$, nitrogen in $\mathrm{ZnO}$ and $\mathrm{SiC}$ and oxygen in $\mathrm{GaN}$ and $\mathrm{SiC}$. Further, the refinements of the SIMS (Secondary Ions Mass Spectrometry) analytical technique, aiming to improve the sensitivity and detection limit of atmospheric elements, are described in detail. These include the choice of primary beam type and current, type of secondary single or cluster ions, geometry and vacuum conditions. Finally, the evaluated so-called RSF parameters (Relative Sensitivity Factors) are given for each atom-semiconductor pair, converting raw data to the absolute value of concentration.
\end{abstract}

DOI: 10.12693/APhysPolA.136.916

PACS/topics: atmospheric elements, wide bang-gap semiconductors, SIMS

\section{Introduction}

All chemical processes may be subject to contamination with elements contained in the Earth atmosphere. In semiconductor technology, hydrogen $(\mathrm{H})$, carbon $(\mathrm{C})$, nitrogen $(\mathrm{N})$ and oxygen $(\mathrm{O})$ appear either as major constituents like in $\mathrm{GaN}, \mathrm{ZnO}, \mathrm{SiC}$ or as trace impurities. Of these, some species are being deliberately introduced in the material forming electrically active dopants while some other can be incorporated from the ambient in an uncontrolled manner. This paper deals with the properties of atmospheric elements in compound semiconductors, their efficiency as acceptors or donors as well as the interaction with different atoms and defects. The contamination by foreign atoms leading to the passivation or compensation of electrical conductivity may take place in processes occurring under atmospheric pressure but also in those conducted under high vacuum, through interaction with residual gases.

Hydrogen is an amphoteric dopant. It can act both as a donor as well as acceptor depending on the material or position in a crystal lattice. In wide band-gap semiconductors hydrogen occurs mostly as a donor, or as a passivating impurity. Carbon due to the place in the Periodic Table is also an amphoteric dopant in III-V and II-VI semiconductors. In GaN and $\mathrm{ZnO}$ it constitutes an active donor or acceptor dopant depending on whether it substitutes cation or anion in the crystal lattice, respectively. As a main component of precursors in MOCVD or residual gasses in MBE method, it also appears as an impurity. Nitrogen is routinely used as an active dopant in both $\mathrm{ZnO}$ as well as $\mathrm{SiC}$ semiconductor material.

*corresponding author; e-mail: jakiela@ifpan.edu.pl
According to its place in the Periodic Table it introduce acceptor carriers in II-VI semiconductors as well as in $\mathrm{ZnO}$, and donor carriers in group IV semiconductor including $\mathrm{SiC}$. So far as the technology of nitrogen-doped $\mathrm{SiC}$ is well established, the research on nitrogen-doped $\mathrm{ZnO}$ is still in development. Oxygen is the most reactive atmospheric element. As a highly abundant impurity is an issue mostly in GaN, introducing donor defects into the layers as well as to bulk materials. The low solubility of oxygen in $\mathrm{SiC}$ implies the lack of active defects influencing the conductivity.

At the same time, the prevalence of atmospheric gases in the measuring devices imposes a detection limit depending on surface adsorption efficiency of the measured material. These applies for most quantitative methods dealing with the measurement of atmospheric elements in solids. The secondary ion mass spectrometry (SIMS) method operating in ultra-high vacuum, using a special arrangement of secondary ion detection is practically the only choice for measuring the dopant content at a ppm level. Other analytical techniques such as Electron Microprobe or Rutherford Backscattering Spectrometry have admittedly ability of quantitative element determination but their sensitivity is far beyond that required for the present study.

\section{Hydrogen}

Hydrogen is one of the most widespread elements on Earth. In the Earth's atmosphere, it occurs bonded with oxygen as water, but its large reservoir is also hydrocarbons being the main component of all fossil fuels. On the other hand, Hydrogen is a common impurity in a number of semiconductors, not only due to its presence in the atmosphere, but also as a component of precursors used for the epitaxy of semiconducting materials. Despite the simple structure (only one proton and one electron) 
hydrogen exhibits very complex behavior. Its ability to bind to broken or weak covalent bonds as found in localized or extended defect centers often results in shifting the defect energy levels from or into the energy gap. This results in passivation or compensation of both shallow and deep defects, but also the creation of extended defects which have a large impact on the electrical and optical properties of semiconductor materials. Hydrogen properties are well established in more traditional semiconductors, such as $\mathrm{Si}$ or GaAs and to a lesser extent in wide band-gap semiconductors, such as gallium nitride $\mathrm{GaN}$, zinc oxide $\mathrm{ZnO}$ or silicon carbide $\mathrm{SiC}$.

Hydrogen, due to its size, in the crystal lattice of the semiconductor usually occupies the interstitial position where can act in three charged states: $\mathrm{H}^{\mathrm{O}}, \mathrm{H}^{+}$and $\mathrm{H}^{-}$. As a result of Coulomb attraction $\mathrm{H}^{+}$(proton) builds into places with high electron density, hence interacts predominantly with anions, whereas $\mathrm{H}^{-}$(proton with 2 electrons) builds into places with low electron density, i.e., connects with cations. Charge of the hydrogen atom in the semiconductor is determined by Fermi's energy level, hence $\mathrm{H}^{+}$is the preferred state in the $p$-type whereas $\mathrm{H}^{-}$ in the $n$-type material. The amphoteric properties of hydrogen atom make it able to compensate both electron and acceptor conductivity.

Chris van der Walle showed [1], that the $\mathrm{H}^{\mathrm{O}}$ state is generally unstable in semiconductors, and the value of the transition energy level between $\mathrm{H}^{+} / \mathrm{H}^{-}$is pined with respect to the vacuum level. Thus, the properties of hydrogen in a given semiconductor depend on the position of the semiconductor energy gap relative to the vacuum level, in the result on such parameters as electron affinity and ionization potential. Therefore depending on the location of the energy gap relative to the vacuum level in a given semiconductor, hydrogen may exhibit acceptor properties as in Ge or GaSb, or donor - as in $\mathrm{InN}$ or $\mathrm{ZnO}$.

\subsection{Hydrogen properties in $G a N$}

The increase of interest in research on hydrogen in gallium nitride occurred when fabrication of GaN based $\mathrm{p}-\mathrm{n}$ junction was attempted. Unfortunately, the magnesium doped GaN layers were highly resistive despite very high dopant concentration. The hydrogen passivation of magnesium, which forms inactive complexes with a dopant was showed by Nakamura [2]. The annealing of the layers at suitable temperature results in the breaking of $\mathrm{Mg}-\mathrm{H}$ bonds and thus the activation of magnesium. Interestingly, subsequent experiments on hydrogen in $\mathrm{GaN}$ at low temperatures showed a complete lack of hydrogen atom mobility up to $900{ }^{\circ} \mathrm{C}$ in $\mathrm{GaN}$ as well as InN or AlN [3]. It would follow that when heating GaN crystals at high temperatures, hydrogen bonds with magnesium are broken, but atoms are not removed from the material. Subsequent studies have shown, that the acceptor conductivity in the GaN layers grown by MBE can be suppressed by introducing hydrogen into the material [4].
The difference of hydrogen mobility in materials with different Fermi levels has been explained from the first principles calculations [5]. Hydrogen as a proton $\mathrm{H}^{+}$prefers the position close to the nitrogen, forming a bond similar to that found in $\mathrm{NH}_{3}$ ammonia. Among the possible positions of both atoms, the nitrogen antibonding site is energetically most stable. Interestingly, this is a different position than in Si or GaAs, due to the polarity of gallium nitride. The activation energy for migration of bound hydrogen as $0.7 \mathrm{eV}$ was calculated. For neutral hydrogen $\mathrm{H}^{\mathrm{O}}$, much smaller energy differences were found according to different sites. The energetically most stable site for $\mathrm{H}^{\mathrm{O}}$ is the Ga antibonding site. For a proton with two electrons $\mathrm{H}^{-}$, the $\mathrm{Ga}$ antibonding site is also energetically most stable, as well as the tetrahedral interstitial site, where the distance between hydrogen and the neighboring $\mathrm{Ga}$ atoms is maximized, and the charge density of the bulk crystal has a global minimum. In this position, the energy barrier for hydrogen migration is as high as $3.4 \mathrm{eV}$. The charge state of hydrogen in GaN affects its diffusion coefficient. In an $n$-type material (e.g., GaN:Si) this parameter is much lower than in a $p$-type material (e.g., GaN:Mg), which was shown by calculations from the first principles [6, 7] and confirmed experimentally in the hydrogen implanted [8], plasma diffused [9-11], or epitaxial [12] GaN layers. The low activation energy for the hydrogen $\mathrm{H}^{+}$diffusion was also shown in experiments on diffusion in the electric potential. Using $p-n$ junction capacity measurements, the activation energy for hydrogen diffusion consisting of the $\mathrm{H}-\mathrm{Mg}$ binding energy $(\sim 1.2 \mathrm{eV})$ and the migration energy $(\sim 0.8 \mathrm{eV})$ was shown [13]. This result was verified to be $1.76 \mathrm{eV}$ in the paper [14]. In the $p$-type material the diffusion coefficient in the nonpolar directions $a-b$ is lower than in the polar direction $c$.

Detailed calculations regarding the anisotropy of the hydrogen diffusion coefficient in GaN were performed by Limpijumnong and Van de Walle [15]. According to the authors, the activation energies of hydrogen in the $\mathrm{H}^{+}$ charge state for diffusion towards or perpendicularly to the $c$-plane are 0.94 or $0.85 \mathrm{eV}$, respectively, while hydrogen $\mathrm{H}^{-}$exhibits the inverse anisotropy and energies are 1.99 or $2.17 \mathrm{eV}$, respectively. Interestingly, according to the calculations, hydrogen has the highest mobility in semi-insulating, $\mathrm{H}^{\mathrm{O}}$ dominated material, because of the lowest activation energies for diffusion in this kind of material. $\mathrm{H}_{2}$ molecule exhibits the activation energies comparable with $\mathrm{H}^{-}$species. Hydrogen diffusion anisotropy was also visible in the activation process of LED GaN:Si/GaN:Mg structures [16]. The direction of the $p$-type layer activation is followed from the side wall to the inside of the structure, which indicates a horizontal diffusion of hydrogen through the structure. The above experiments and calculations show that hydrogen can be introduced and removed from the $p$-type material, while it is completely immobile in the $n$-type material. The annealing of the material in $\mathrm{N}_{2}$ ambient at temperatures over $700^{\circ} \mathrm{C}$ is a standard procedure for removing 
hydrogen from GaN:Mg layers, which has already been demonstrated at the first stage of research on acceptor doping of GaN [17]. Subsequent studies have also shown alternative methods of $\mathrm{Mg}$ activation in GaN. Those are: annealing under the $\mathrm{O}_{2}$ atmosphere at the temperature over $400^{\circ} \mathrm{C}[18,19]$ or under $\mathrm{NF}_{3}$ ambient at the temperature over $850^{\circ} \mathrm{C}[20]$.

The next important parameter associated with the dopant incorporation is the formation energy of a defect. Theoretical calculations showed [21-23], that the formation energy of $\mathrm{H}^{+}$increases with Fermi level, reaching almost $2 \mathrm{eV}$ in the $n$-type material. It is opposite to the hydrogen in the $\mathrm{H}^{-}$charge state, where the formation energy decreases from $\sim 2$ to $\sim 1 \mathrm{eV}$ with the increase of the Fermi level. These results well explain the lack of hydrogen in the $n$-type material and a large amount of hydrogen in the $p$-type material, where $\mathrm{H}^{-}$exhibits the negative formation energy. Epitaxial growth of the $n$-type material even by MOCVD method employing $\mathrm{H}$-contained precursors, results in no hydrogen incorporation or diffusion. The results of SIMS measurements of MOCVD layers indicate the hydrogen concentrations at the level below the detection limit. On the contrary, in the $p$-type layers hydrogen is easily incorporated into the material, passivating the acceptor dopants. One exception is the MBE method, in which high vacuum allows to grow magnesium doped nitride layers free of hydrogen. Nevertheless, the high hydrogen content in atmosphere and the high diffusion coefficient $\left(>10^{11} \mathrm{~cm}^{2} / \mathrm{s}\right)$ make it possible to contaminate the semiconductor materials at many stages of the semiconductor devices manufacture [24].

Hydrogen may be present in GaN also in molecular form, as confirmed by means of infrared spectroscopy [25], having the most stable position in semiinsulating material [22]. The $\mathrm{H}_{2}$ molecule at the interstitial site can also cause tensile stress of the GaN lattice crystal, as was observed in the MBE layers with hydrogen content exceeding a certain critical value [26].

In conclusion, hydrogen in GaN mainly causes the compensation of $p$-type layers having the highest diffusion coefficient in this type of material. Therefore the elevated temperatures and appropriate annealing conditions are required to remove it from the material.

\subsection{Hydrogen properties in $\mathrm{ZnO}$}

According to the description of the hydrogen properties in semiconductors by Van de Walle [1] hydrogen atom in $\mathrm{ZnO}$ always exhibits donor properties with $\mathrm{H}^{+} / \mathrm{H}^{-}$transition level in the conduction band. It is worthwhile noting that the beginning of research on the hydrogen properties in $\mathrm{ZnO}$ dates to the 50's [27, 28], when the technology of semiconductors such as $\mathrm{Si}$ or GaAs was still in its infancy. The activation energy of hydrogen as a donor was then calculated on $0.04 \mathrm{eV}$. Hydrogen in $\mathrm{ZnO}$ is usually an impurity and incorporate into the material either from residual gases, as in the $\mathrm{MBE}$ and magnetron sputtering method or from hydrogen contained precursors, as in the Metaloorganic Chemical Vapor
Depositon (MOCVD) and Atomic Layer Deposition (ALD) methods. The calculation from the first principles confirming the shallow state of hydrogen donor was reported by Van de Walle [29]. Hydrogen in the $\mathrm{H}^{-}$charge state occurs in the $p$-type material with the formation energy of $-2 \mathrm{eV}$ at $\mathrm{E}_{\mathrm{F}}=\mathrm{E}_{\mathrm{V}}$ and is stable over the entire Fermi level range in the band gap. According to calculations of Van de Walle, molecular hydrogen in $\mathrm{ZnO}$ can be formed in the material only in the narrow range of Fermi level $\sim 3 \mathrm{eV}$ above the valence band, while $\mathrm{H}^{-}$in the $n$-type material with the formation energy of $0.5 \mathrm{eV}$ at $\mathrm{E}_{\mathrm{F}}=\mathrm{E}_{\mathrm{C}}$. The possible hydrogen locations in the $\mathrm{ZnO}$ crystal lattice was shown, with the most stable bond centered interstitial position between $\mathrm{O}$ and $\mathrm{Zn}$ atoms, perpendicular to the $c$ axis. Possible relaxation of the lattice caused by the defect was also noted. Similar calculations were made by authors of [30], with the results indicating on the more stable interstitial hydrogen site located at the $\mathrm{O}-\mathrm{Zn}$ bond parallel to the $c$ axis. The hydrogen interstitial position has been confirmed experimentally in numerous studies by infrared spectroscopy or Raman spectroscopy. Infrared absorption peaks were observed for $\mathrm{H}-\mathrm{O}$ complex in anti-bonding configuration, oriented at an angle of $110^{\circ}$ from the $c$ axis [31-33]. Configuration of interstitial hydrogen, indicating also the presence of another $\mathrm{H}-\mathrm{O}$ bond parallel to the $c$ axis was confirmed in [34-36]. Annealing of $\mathrm{ZnO}$ samples in the atmosphere free of hydrogen provides the formation of donors associated with hydrogen. It would indicate the presence of $\mathrm{H}$ in the $\mathrm{ZnO}$ material in a other configuration than that observed in infrared absorption spectra. It is supposed to be molecular hydrogen $\mathrm{H}_{2}$. These predictions have been confirmed by Raman spectroscopy [37, 38]. Such amphoteric properties of hydrogen were also well acknowledged in theoretical calculations [39].

The hydrogen diffusion parameters in $\mathrm{ZnO}$ have been determined in the very first studies on the properties of $\mathrm{H}$ in $\mathrm{ZnO}[27,28]$. Similar diffusion activation energies of 1.12 and $0.91 \mathrm{eV}$, respectively, were received. The obtained energies are similar to the results inferred from the first principles calculations [30] for interstitial and $\mathrm{H}_{\mathrm{O}}$ substitutional diffusion of hydrogen and amount $\sim 0.5$ and 1.7 eV respectively. Diffusion was not observed in the hydrogen implanted samples [40, 41]. In these cases hydrogen is predominantly located in implantation generated defects thereby forming less mobile molecules such as $\mathrm{H}_{2}$ and ultimately outdiffuse from the layer at higher temperatures [42]. Rapid hydrogen diffusion in $\mathrm{ZnO}$ layers was confirmed by annealing in hydrogen plasma $[43,44]$. However, very high diffusion coefficients indicate polycrystalline structure of the medium. Hydrogen indiffusion into $\mathrm{ZnO}$ crystal by passing the electron current through the sample was also shown in [45].

In summary, hydrogen in zinc oxide act as a donor, significantly counteracting doping of the $p$-type material. Moreover, it has a very high diffusion coefficient in $\mathrm{ZnO}$, which makes possible to remove it from the samples by annealing at the temperatures as low as $500-600^{\circ} \mathrm{C}$. 


\subsection{Hydrogen properties in $\mathrm{SiC}$}

The pioneering characterization of hydrogen in $\mathrm{SiC}$ was conducted by Choyke and Patrick, by studying the photoluminescence at $1.4 \mathrm{~K}$ in hydrogen or deuterium implanted 6H-SiC samples [46]. Carbon bound hydrogen was observed based on spectral line shifts between samples containing different isotopes. The annealing of the implanted samples at $800^{\circ} \mathrm{C}$ caused an increase in the intensity of the photoluminescence. It was explained by diffusion of hydrogen into the substitution sites $\mathrm{H}_{\mathrm{Si}}$ and increasing the number of bonds with carbon. A similar mechanism was confirmed in polytypes $4 \mathrm{H}$ and 15R [47]. However, theoretical work pointed on the interstitials hydrogen site in cubic as well as hexagonal crystals [48].

Further studies were oriented to the hydrogen-induced dopant passivation in silicon carbide. The passivation level of both acceptor and donor dopants in $6 \mathrm{H}-\mathrm{SiC}$ crystals were evaluated to $75 \%$ using the electron spin resonance (ESR) method [49] after annealing under hydrogen atmosphere in the temperature range of $1500-1700{ }^{\circ} \mathrm{C}$. The inverse process can be achieved by annealing in argon. Passivation of dopants by hydrogen is of key importance especially in chemical vapor deposition (CVD) techniques, where the precursors of both matrix elements $\left(\mathrm{SiH}_{4}\right.$ silane, $\mathrm{C}_{3} \mathrm{H}_{8}$ propane) and dopant (diborane $\mathrm{B} 2 \mathrm{H} 6$ ) contain hydrogen, which results in easy incorporation of $\mathrm{H}$ in epitaxial layers [50]. Subsequent studies have shown that the passivation efficiency of acceptors is much higher than donors. Such behavior is quite common in semiconductors and is related to the more stable bond centered hydrogen position bound to acceptor compared to the anti-bonding interstitial position when binding to the donor. In the case of acceptors, the estimated reactivation energy is $3.3 \mathrm{eV}$.

The results of the early papers on hydrogen diffusion in $\mathrm{SiC}$ showed no $\mathrm{H}$ redistribution up to $1000^{\circ} \mathrm{C}$ in the deuterium implanted layers. Simultaneously, the diffusion of hydrogen into the $\mathrm{SiC}$ bulk crystal during the sample annealing under hydrogen plasma, was revealed by the SIMS measurement [51]. The subsequent results obtained on deuterium implanted samples indicated high hydrogen mobility in $\mathrm{B}$ or $\mathrm{Al}$ doped samples, resulting in complete passivation of acceptor dopants, and a complete lack of diffusion in samples with $n$-type conductivity at the temperatures range up to $300^{\circ} \mathrm{C}[52-54]$. In the review paper $[55,56]$ the concentration dependent diffusion of hydrogen, where the diffusion coefficient depends on the concentration of hydrogen trapping acceptor dopant was pointed out. The calculated dissociation energy of $\mathrm{H}-\mathrm{B}$ and $\mathrm{H}-\mathrm{Al}$ hydrogen complexes amount of 2.51 and $1.61 \mathrm{eV}$ respectively and indicate the different atomic configuration of both complexes. Moreover, the bond length of the boron complex indicates the Coulomb interaction of both atoms. This type of interaction was pointed out by Van de Walle in his theoretical work [1]. Efficient passivation results from the fact that the ionized dopant interacts with hydrogen by the Coulomb's far-range interaction, while in the case of proton (acceptor) or hydrogen with an additional electron (donor), makes it easier to find $\mathrm{H}$ close to the dopant. Another trap center for hydrogen in $\mathrm{SiC}: \mathrm{Al}$ was determined by authors of [57]. The annealing of $\mathrm{Al}$ doped layers at low temperatures leads to the dissociation of hydrogen bonds with aluminum and formation of complex with silicon vacancy $\mathrm{V}_{\mathrm{Si}}-\mathrm{H}$. The high mobility of hydrogen in $\mathrm{SiC}$ with either type of conductivity, but at temperatures above $1000{ }^{\circ} \mathrm{C}[58]$ was demonstrated and the difference in the diffusion coefficient depending on the electrical properties of the semiconductor was confirmed. In the $p$-type material, where hydrogen is present as a proton, the diffusion range at the temperature $1000^{\circ} \mathrm{C}$ during $1 \mathrm{~h}$ annealing is $\sim 0.5$ microns higher than in $n$-type material. Both depth profiles exhibit a characteristic drop in concentration, indicating diffusion described by concentration dependent diffusion coefficient.

Such characteristic profiles appear in the case of various dopants in various crystal materials and indicate that the atom diffusion is determined by an additional factor reducing the atom mobility [59-62]. The influencing factors can be level of dopant trapping defects resulting from the Fermi level, the charge state of defects affecting they mobility, which may also result from the Fermi level or as in the case $\mathrm{SiC}$, the dopant forming complexes with diffusing atoms. Then, the hydrogen diffusion proceeds as follows, hydrogen atoms diffusing into subsequent layers of the semiconductor first passivates the dopants becoming less mobile, then saturating all defects; the excess of atoms diffuse deeper and the process repeats. The characteristic drop of the hydrogen depth profile occurs at the $\mathrm{H}$ concentration level equals to the acceptor or donor concentration. The diffusion coefficient is higher for boron doped material, indicative of lower H-B binding energy compared to the $\mathrm{H}-\mathrm{N}$. Our results [58] also indicate that the diffusion of hydrogen in $\mathrm{SiC}$ take place with the contribution of point defects produced by post-implantation damage, because the diffusion process takes place only towards the high concentration of defects. In addition, defects arising from the implantation process also cause oxygen segregation [63].

In the above presented configurations, the presence of hydrogen in the semiconductor exhibits, in general, an undesirable effect. Conversely, in some applications hydrogen is intentionally introduced into semiconductor materials. Hydrogenated amorphous silicon is used in photovoltaic cells [64], various materials are implanted with hydrogen to separate thin layers and transfer them to other substrates, as in the technology of Silicon on Insulator (SOI) [65].

\subsection{Hydrogen measurement by SIMS}

SIMS is one of the few methods which can measure the hydrogen content in materials. It also provides the lowest hydrogen detection limit. However, it should be noted that due to the prevalence of hydrogen in the ambient atmosphere - mainly due to the water vapor, the detection limit strongly depends on the vacuum 

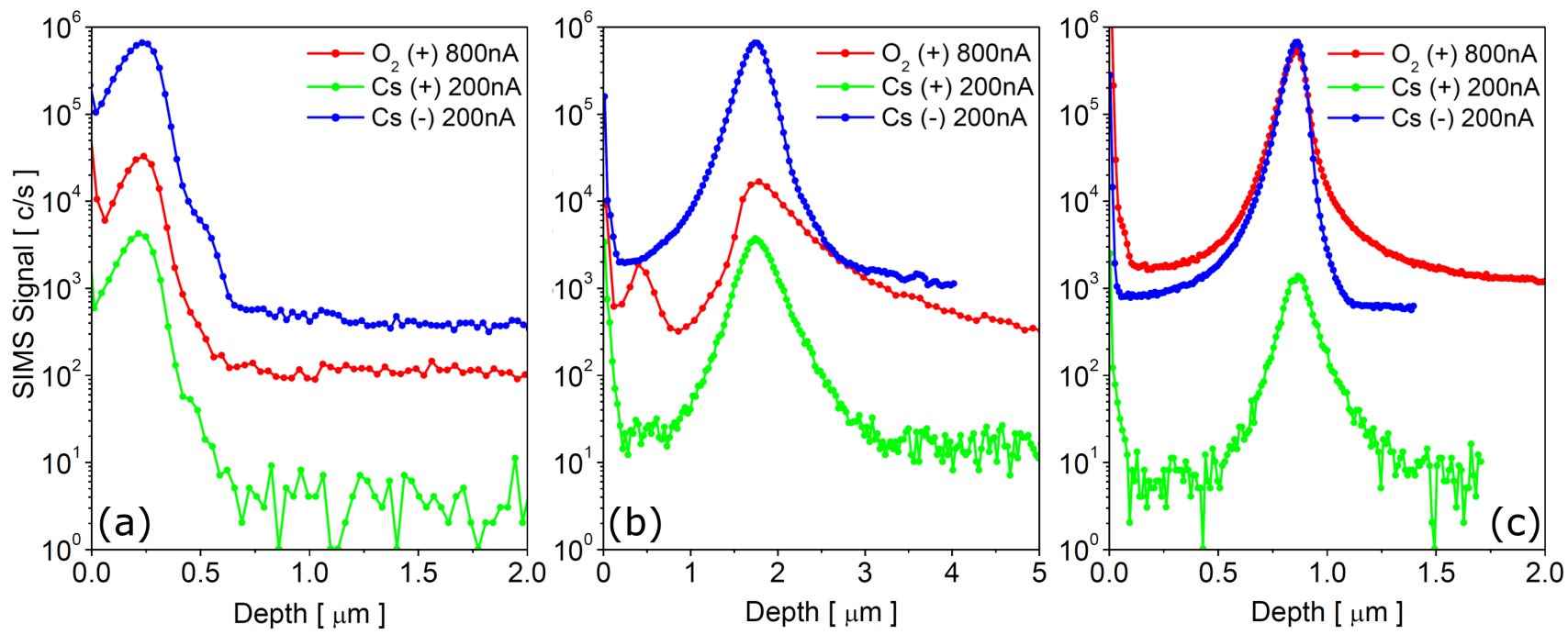

Fig. 1. Depth profiles of hydrogen implanted into 3 different materials, as measured under 3 different measurement condition: (a) GaN $\left(D=1 \times 10^{16} \mathrm{~cm}^{-2}, E=25 \mathrm{keV}\right)$, (b) $\mathrm{ZnO}\left(D=1 \times 10^{16} \mathrm{~cm}^{-2}, E=250 \mathrm{keV}\right)$, (c) SiC $\left(D=1 \times 10^{16} \mathrm{~cm}^{-2}, E=150 \mathrm{keV}\right)$.
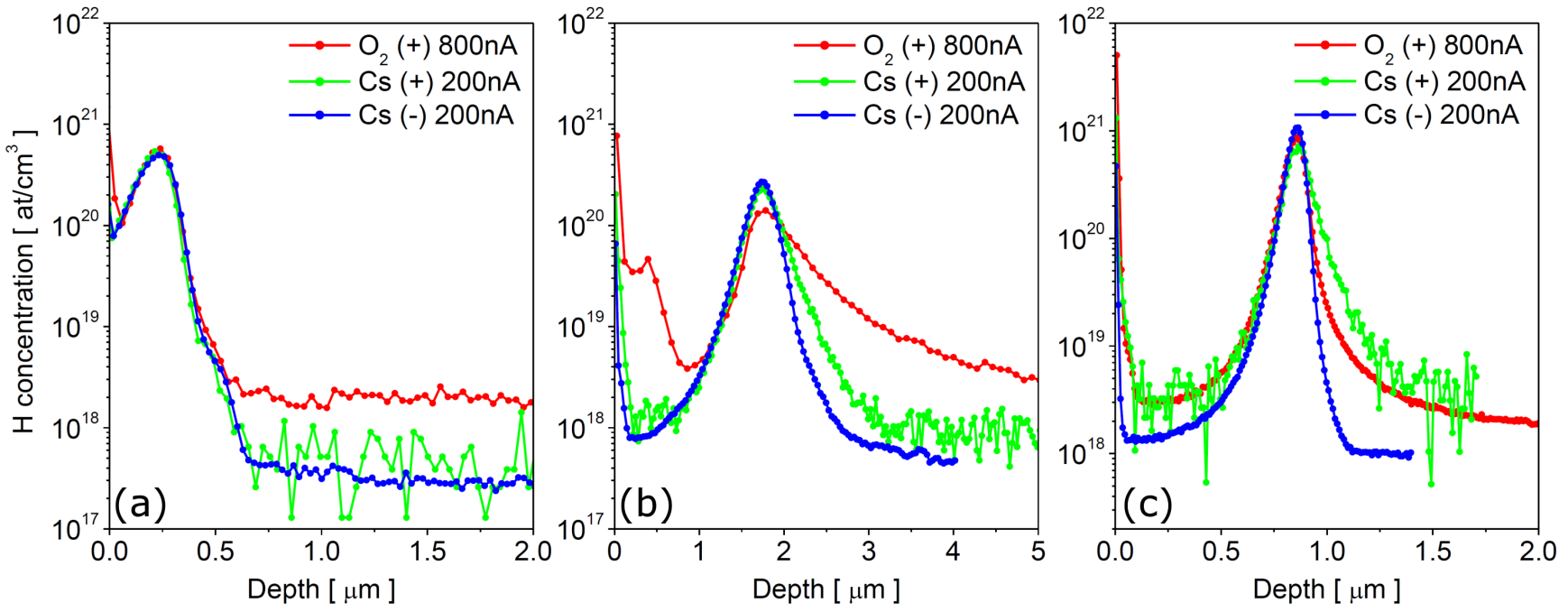

Fig. 2. Hydrogen depth profiles in concentration values: (a) GaN $\left(D=1 \times 10^{16} \mathrm{~cm}^{-2}, E=25 \mathrm{keV}\right)$, (b) ZnO $\left(D=1 \times 10^{16} \mathrm{~cm}^{-2}, E=250 \mathrm{keV}\right),(\mathrm{c}) \mathrm{SiC}\left(D=1 \times 10^{16} \mathrm{~cm}^{-2}, E=150 \mathrm{keV}\right)$.

conditions in the measuring apparatus. Hydrogen in solids is detected by SIMS as both the positive ion $\mathrm{H}^{+}$ (proton) and the negatively ionized $\mathrm{H}^{-}$(proton with 2 electrons). However, much better detection of the element takes place when measuring the negative ion, which results from the fact that the ionization yield of the $\mathrm{H}^{-}$ion is about 2 orders higher than the $\mathrm{H}^{+}$ion. This is mainly due to hydrogen properties. The hydrogen ionization energy is equal to the Rydberg constant (Ry) and amount $13.6 \mathrm{eV}$, but its electron affinity is only $0.75 \mathrm{eV}$. On Figs. 1 and 2 the comparison of SIMS hydrogen measurements in hydrogen implanted $\mathrm{GaN}, \mathrm{ZnO}$ and $\mathrm{SiC}$, under three measurement conditions is showed:
1. $\mathrm{O}_{2}^{+}$beam at the energy of $8 \mathrm{keV}$, positive ions $\mathrm{H}^{+}$ collected, primary beam current at $800 \mathrm{nA}$, sputtered area $R=200 \times 200 \mu \mathrm{m}^{2}$;

2. $\mathrm{Cs}^{+}$beam at the energy of $5.5 \mathrm{keV}$, positive ions $\mathrm{H}^{+}$ collected, primary beam current at $200 \mathrm{nA}$, sputtered area $R=200 \times 200 \mu \mathrm{m}^{2}$;

3 . $\mathrm{Cs}^{+}$beam at the energy of $14.5 \mathrm{keV}$, negative ions $\mathrm{H}^{-}$collected, primary beam current at $200 \mathrm{nA}$, sputtered area $R=200 \times 200 \mu \mathrm{m}^{2}$.

During the hydrogen measurement in a thin layer, the detection limit is restricted by the primary beam current density, which should not be too high to achieve appropriate depth resolution in the dynamic SIMS measurement. 


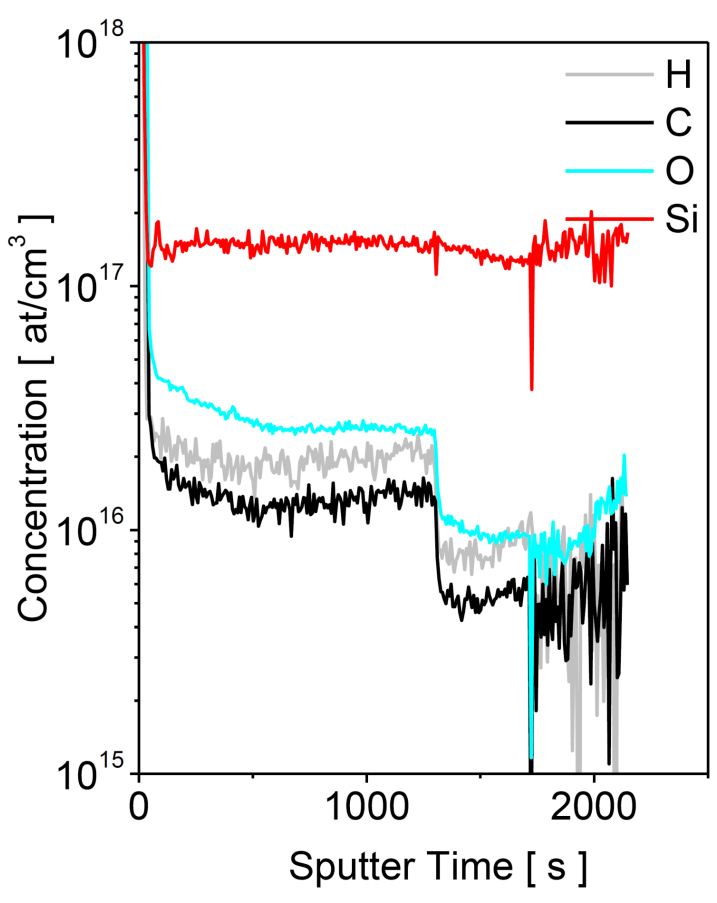

Fig. 3. Depth profile of H, C, O and Si in the HVPE bulk GaN material.

Therefore, the hydrogen detection limit for such a measurement places in the range of $10^{17}-10^{18}$ at $/ \mathrm{cm}^{3}$ as in the case of GaN:Mg layers [11, 66, 67]. For the GaN bulk material, the use of a primary beam with high current density can significantly lower this parameter. The lowest detection limit of hydrogen in $\mathrm{GaN}\left(8 \times 10^{15} \mathrm{at} / \mathrm{cm}^{3}\right)$ was achieved in the hydride vapor phase epitaxy (HVPE) material (Fig. 3).

The result was obtained by sputtering the material with a $\mathrm{Cs}^{+}$beam at a primary beam current of $500 \mathrm{nA}$ over the area $50 \times 50 \mu \mathrm{m}^{2}$ [68]. The drops in the SIMS signals of the atmospheric elements are caused by the increase of the current density during the measurement (intentional reduction of the sputtered surface area). If the measured signals originate from residual gas atoms adsorbed on the sample surface, increasing the primary beam current density increases the reference signal without affecting the SIMS signal of the measured element. A correspondingly higher reference signal after the conversion to absolute values corresponds to a lower concentration of the measured elements. It is worth noting that in the case of $\mathrm{Si}$, whose signal corresponds to an exact element content in the material, the effect does not occur. It means that the increased primary beam current density equally affected the increase of the $\mathrm{Si}$ and the reference signal.

Hydrogen measurements in $\mathrm{ZnO}$ layers and bulk crystals exhibit both the ion yield as well as detection limit similar to GaN. However, the SIMS measurement of hydrogen in $\mathrm{ZnO}$ with the detection limit as low as in GaN has not been documented so far. This is mainly due to the fact that the as high purity of $\mathrm{ZnO}$ crystals has not yet been reached as in the case of GaN crystals in terms of hydrogen content. Therefore, the first measurements of $\mathrm{H}$ diffusion in $\mathrm{ZnO}$ layers by the SIMS method were done using deuterium, which has an abundance of 4 orders of magnitude lower than the main isotope. Nevertheless, the detection limit for deuterium measurements in $\mathrm{ZnO}$ layers was not lower than $10^{15}$ at $/ \mathrm{cm}^{3}$ [40, 44], which corresponds to the concentration of $10^{19} \mathrm{at} / \mathrm{cm}^{3}$ for the main hydrogen isotope. Ultra high vacuum conditions in our SIMS apparatus and properly pure material allowed us to measure hydrogen in the $\mathrm{ZnO}$ crystal at the concentration level of $2 \times 10^{17}$ at $/ \mathrm{cm}^{3}$. The sample was sputtered with a $\mathrm{Cs}^{+}$beam at the primary beam current of $300 \mathrm{nA}$ over the area of $100 \times 100 \mu \mathrm{m}^{2}$. Due to the presence of hydrogen in precursors in $\mathrm{ZnO}$ growth methods like atomic layer deposition (ALD), the $\mathrm{H}$ content in the layers grown by ALD can exceed the concentration of $10^{21}$ at $/ \mathrm{cm}^{3}$ [69-71]. Thus, the measurement of hydrogen concentration in ALD layers can be provided by collecting protons $\mathrm{H}^{+}$, which allows measuring the hydrogen depth profiles simultaneously with $\mathrm{Cr}$ [72], $\mathrm{Ag}$ [73], Co [74] or $\mathrm{Al}$ and $\mathrm{Ga}$ [75]. The detection limit of hydrogen under such measurement conditions provides the level of $10^{18}$ at $/ \mathrm{cm}^{3}$ [76]. Similar parameters are obtained when measuring thin layers grown by molecular beam epitaxy (MBE) method [77] due to the low primary beam current density and thus the correspondingly low sputter rate.

Hydrogen measured as $\mathrm{H}^{-}$in the silicon carbide has a comparable ion yield as for the two previous materials (Fig. 1). Because of low hydrogen content in bulk SiC crystals, the first research on the hydrogen properties in $\mathrm{SiC}$ showed the SIMS measurements results providing the hydrogen detection limit at the concentration level of $10^{17} \mathrm{at} / \mathrm{cm}^{3}$ [50]. The use of deuterium implanted epitaxial layer to characterize hydrogen diffusion, allowed to lower this level to $6 \times 10^{14}$ at $/ \mathrm{cm}^{3}$ [52]. Similarly to $\mathrm{ZnO}$, the dopant does not exhibit 4 order of magnitude lower detection limit, as it should be expected from the abundance ratio of both isotopes. This is mainly due to low primary beam current density used for SIMS measurements needed for the observation of shallow (nanometer scale) diffusion ranges of deuterium in $\operatorname{SiC}[51,52,56]$. SIMS measurements done with the cesium primary beam with the ion current kept in the range of 200-250 nA and the sputtered the area of $150 \times 150 \mu \mathrm{m}^{2}$, allowed to achieve the detection limit at the concentration level of $2 \times 10^{17}$ at $/ \mathrm{cm}^{3}$ [58].

In summary, SIMS as one of the few measurement methods capable of the determination of the absolute hydrogen content in semiconductors, achieving concentration detection limit in some materials below $10^{16}$ at $/ \mathrm{cm}^{3}$. Moreover, the oxygen beam or a cesium beam at a lower energy $(\leq 5.5 \mathrm{kV})$ can be used for hydrogen measurement in very thin layers. It allows providing the $\mathrm{H}$ depth profiles with higher depth resolution, without significantly losing the detection limit. It shout be noted that secondary ions yield is proportional to the content 
TABLE I

Isotope RSF's for hydrogen as measured on CAMECA IMS $6 \mathrm{~F}, \mathrm{Cs}+(14.5 \mathrm{keV})$, neg.

\begin{tabular}{c|c|c}
\hline \hline $\mathrm{H}$ in GaN & $\mathrm{H}$ in $\mathrm{ZnO}$ & $\mathrm{H}$ in $\mathrm{SiC}$ \\
in reference & $\begin{array}{c}\text { in reference } \\
\text { to }{ }^{69} \mathrm{Ga}^{-}\end{array}$ & $\begin{array}{c}{ }^{64} \mathrm{Zn}_{2}^{16} \mathrm{O}_{2}^{-} \\
\text {in reference } \\
\text { to }{ }^{30} \mathrm{Si}_{2}^{-}\end{array}$ \\
\hline $2 \times 10^{20}$ & $6 \times 10^{20}$ & $6 \times 10^{20}$
\end{tabular}

of a given element. To convert these raw data to absolute values of concentration so called RSF (Realtive Sensitivity Factor) shoud be evaluated for all the species/material pair. Usually this figures can be obtained by measuring standards with known concentration of ion-implanted semiconductors.

Table I lists the isotope RSF's for hydrogen as measured with CAMECA IMS6F using $\mathrm{Cs}^{+}$primary beam at the energy of $14.5 \mathrm{keV}$ in $\mathrm{GaN}, \mathrm{ZnO}$ or $\mathrm{SiC}$.

\section{Carbon}

Carbon is the building element of all organic compounds. Oxidized as $\mathrm{CO}_{2}$ is also a breathing product of a large majority of living organisms, as well as the burning product of organic substances and fossil fuels. Hence, its universality in the atmosphere, where it mainly occurs in the form of $\mathrm{CO}_{2}$.

Carbon place in the periodic table (group IV) implies that in most semiconductors it acts as an amphoteric dopant, which means that depending on its position in the crystal lattice it can be either a donor or an acceptor. This applies to both main growth methods: metaloorganic chemical vapor deposition (MOCVD), where the carbon atoms are component of the precursors used in the epitaxy process, as well as the MBE method, where it is a residual gas component as $\mathrm{CO}_{2}$.

\subsection{Carbon properties in $G a N$}

Carbon in the best researched III-V semiconductor GaAs, prefers the substitutional position for the anion and are used as an intentional acceptor dopant [78]. In one of the first photoluminescence measurements of GaN:C layers grown by gas phase epitaxy it was shown that the carbon atom may act as shallow acceptor [79]. The calculated activation energy of the dopant based on optical measurements was $230 \mathrm{meV}$. Another theoretical work concluded, that although the carbon atom prefers a substitutional site for nitrogen due to comparable sizes, it creates an acceptor $\mathrm{E}_{\mathrm{V}}+0.2 \mathrm{eV}$ in nitrogen substitutional site $\left(\mathrm{C}_{\mathrm{N}}\right)$, or donor $\mathrm{E}_{\mathrm{C}}-0.2 \mathrm{eV}$ in gallium substitutional site $\left(\mathrm{C}_{\mathrm{Ga}}\right)$ [80]. Due to the wide bandgap of $\mathrm{GaN}$, the formation of electrically active defects compensating the intentional conductivity is particularly strong. The donor formation energy $\mathrm{C}_{\mathrm{Ga}}^{+}$in the $p$-type material is low due to electron transfer from the donor level to the valence band. The same is valid for the acceptor $\mathrm{C}_{\mathrm{N}}^{-}$in $n$-type material (Fig. 4a). The transfer of the electron from the donor to the acceptor state causes a strong
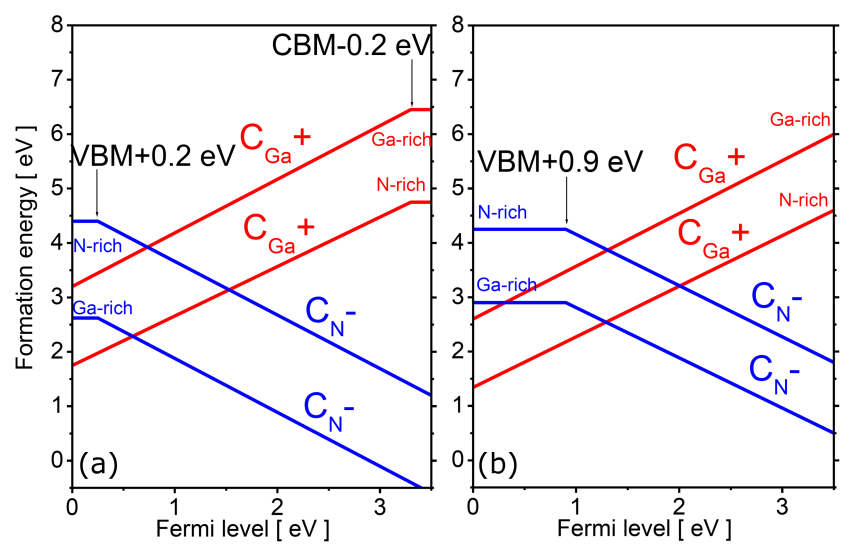

Fig. 4. Formation energies as a function of Fermi level for carbon dopant in GaN under Ga-rich and N-rich conditions, as taken from: (a) ref. [85], (b) ref. [88]. The zero of Fermi level corresponds to the top of the valence band.

Coulomb attraction, and thus the formation of $\mathrm{C}_{\mathrm{N}}-\mathrm{C}_{\mathrm{Ga}}$ pairs. The compensating properties of acceptors resulting from carbon doping were shown in high-resistive layers grown by MOCVD [81], MBE [82], as well as HVPE method [83]. Comparison of data inferred from the density functional theory calculations with the results obtained from optical and electrical measurements confirmed the incorporation of carbon in the nitrogen site in GaN:Si $n$-type samples, leading to partial electrical compensation of such layers [84]. However, when the concentration of carbon exceeds the concentration of silicon, the carbon atoms was observed to build into both substitutional sites and the GaN becomes semi-insulated. This is due to the equalization of the formation energy of both defects. In such material, the additional photoluminescence peak at the energy of $3 \mathrm{eV}$ has appeared.

In addition to carbon in substitutional positions and carbon complexes, also the interstitial position of the atom was considered by authors of $[85,86]$. In the first paper, as many as 5 interstitial dopant positions were distinguished: one for the atom in the crystal lattice channel in the direction of the $c$ axis, and 4, where the carbon atoms share the substitutional site with the nitrogen atom (split-interstitials), having in each configuration a different charge state. Considering the formation energy of a particular interstitial defect, the carbon in the channel position is formed at low Fermi level ( $p$-type material), while one of the split-interstitials defects with nitrogen $\mathrm{C}_{\mathrm{i}}^{2-}$ — at high Fermi level ( $n$-type material).

The previous findings were impaired by the studies based on hybrid functional calculation (HFC) [87], considering carbon as a shallow acceptor in GaN. It was showed that the transition level between neutral and ionized substitutional defect $\left(\mathrm{C}_{\mathrm{N}}^{\mathrm{O}} / \mathrm{C}_{\mathrm{N}}^{-}\right)$appears at $0.9 \mathrm{eV}$ above the valence band, which means that carbon act as a deep acceptor (Fig. 4b). Additionally, such configuration explains the long-discussed yellow luminescence in GaN:C [88]. Measurements using deep level optical 
spectroscopy (DLOS) and deep level transient spectroscopy (DLTS) methods [89] confirmed the deep acceptor level of the $\mathrm{C}_{\mathrm{N}}$ defect and showed the origin of yellow luminescence at the energy of $2.2 \mathrm{eV}$ based on coordinating diagram.

The properties of carbon complexes with particular vacancies and dopants such as $\mathrm{H}, \mathrm{O}$ and $\mathrm{Si}$ was given by Matsubar and Bellotti in a two-part publication [90, 91]. Improvement of epitaxial growth techniques resulted in efficiency improvement of carbon doping of GaN. The concentration of dopants at the level of $10^{20} \mathrm{at} / \mathrm{cm}^{3}$ with $10 \%$ activation of acceptors using the $\mathrm{CBr}_{4}$ precursor in the PA-MBE method was reported [92]. However, for the MOCVD growth method, the literature was focused on controlling unintentional carbon incorporated during GaN layer growth, because of carbon-contained organometallic precursors [93-95].

In conclusion, owing to its amphoteric properties in III-V semiconductors, carbon is preferably suited for the compensation of conductivity and thus the production of highly resistive crystals. The technology for the growth of GaN:C semiconducting layers requires further research.

\subsection{Carbon properties in $\mathrm{ZnO}$}

In contrast to III-V, in II-VI materials carbon is no longer a typical dopant, since substituting any of the atoms of II-VI compound it acts as double donor (substitution of a cation), or a double acceptor (substitution of anion). In general, it has a strong influence on the electrical conductivity, especially in materials grown by MOCVD method carbon is the main component of the organometallic precursors.

The calculations regarding the position of carbon in the $\mathrm{ZnO}$ crystal lattice showed that it substitutes the oxygen atom, but not as a single atom, but as a constituent of the diatomic molecules $\mathrm{C}-\mathrm{O}$ or $\mathrm{C}-\mathrm{N}$ [96]. According to the calculations, $\mathrm{CO}_{\mathrm{O}}$ complex forms a deep donor state, whereas the $\mathrm{CN}_{\mathrm{O}}$ complex is located in conducting band. Interestingly, the bond length of these molecules differs only by a few percents from the bond length of free $\mathrm{C}-\mathrm{O}$ or $\mathrm{C}-\mathrm{N}$ dimers. The $\mathrm{C}-\mathrm{N}$ dimer exhibits the lower formation energy but it occurs only in nitrogen doped samples. Moreover, in the material with low Fermi level, the formation energy of $\mathrm{C}-\mathrm{N}$ defect is lower than that of the substitutional defect $\mathrm{N}_{\mathrm{O}}$, what may result in acceptor compensation. The results of theoretical calculations have been confirmed experimentally in $\mathrm{ZnO}$ layers grown by the MOCVD method [97, 98]. The existence of carbon in the interstitial position with very high formation energy exceeding $2 \mathrm{eV}$ and $4 \mathrm{eV}$ in $p$-type and $n$-type material respectively, were also postulated. Appropriate annealing of unintentional carbon doped layers grown by MOCVD method allows to obtain a $p$-type material [99]. It results from the carbon in the zinc substitutional position $\mathrm{C}_{\mathrm{Zn}}$, which may create a complex with two interstitial oxygen atoms $\mathrm{C}_{\mathrm{Zn}}-\mathrm{O}_{\mathrm{i}}$ forming the acceptors with the activation energy of $0.057 \mathrm{eV}$. The same defect without interstitial oxygen act as a donor. Donor defect $\mathrm{C}_{\mathrm{Zn}}$ exhibits a low formation energy in $p$-type material, while the acceptor defect $\mathrm{C}_{\mathrm{Zn}}-\mathrm{O}_{\mathrm{i}}$ in the $n$-type material, has energy $2 \mathrm{eV}$ lower than $\mathrm{C}_{\mathrm{Zn}}$ defect. The formation energy of both defects increases upon annealing under the atmosphere with low chemical potential of oxygen $(\sim 5 \mathrm{eV}$ for $\mathrm{C}_{\mathrm{Zn}}-\mathrm{O}_{\mathrm{i}}$ and $\sim 2 \mathrm{eV}$ for $\mathrm{C}_{\mathrm{Zn}}$ ).

The research on the acceptor dopants in $\mathrm{ZnO}$ is connected with the discussion about the source of green luminescence in the material. In this context, carbon complexes were postulated basing on calculations using the HFC method [100]. Carbon in oxygen substitutional position associated with oxygen vacancy or interstitial zinc $\mathrm{C}_{\mathrm{O}}-\mathrm{V}_{\mathrm{O}}, \mathrm{C}_{\mathrm{O}}-\mathrm{Zn}_{\mathrm{i}}$ was proposed as responsible for the green luminescence. Both defects are formed the most efficiently during the annealing of $\mathrm{ZnO}$ under the conditions of low oxygen chemical potential. Similar conclusions were given by authors of [101], confirming the presence of the $\mathrm{C}_{\mathrm{O}}-\mathrm{Zn}_{\mathrm{i}}$ defect revealed from electron spin resonance (ESR) measurements.

The magnetic properties of both $\mathrm{ZnO}: \mathrm{C}$ layers $[102,103]$ as well as in nanocrystals [104] were also found, showing the magnetic moment amount of $1.35 \mu_{\mathrm{B}}$ per carbon atom, at the Curie temperature higher than room temperature.

In conclusion, the properties of carbon in $\mathrm{ZnO}$ crystals are still poorly understood. The research indicates that it creates active carriers only in complexes with other defects. An interesting issue requiring investigation is its ability to act as a double acceptor in the case of the effective incorporation into the oxygen site.

\subsection{SIMS measurement of carbon}

The group IV elements exhibit high electron affinity, therefore in the SIMS method their ion yield is higher for negative than positive ions. Carbon has the highest electron affinity $(1.6 \mathrm{eV})$ from all elements except group VI and VII of the Periodic Table. It exhibits also one of the highest ionization potential $(11.3 \mathrm{eV})$. Hence, the best detection of carbon in the SIMS method is achieved when the material is sputtered using a cesium beam and carbon negative ions or carbon contained ion clusters are collected. Figures 5 and 6 show the depth profiles of carbon implanted into $\mathrm{GaN}$ or $\mathrm{ZnO}$ under three measurement conditions:

1. $\mathrm{O}_{2}^{+}$beam at the energy of $8 \mathrm{keV}$, positive ions collected, primary beam current at $800 \mathrm{nA}$, sputtered area $\mathrm{R}=200 \times 200 \mu \mathrm{m}^{2}$,

2. $\mathrm{Cs}^{+}$beam at the energy of $5.5 \mathrm{keV}$, positive ions collected, primary beam current at $200 \mathrm{nA}$, sputtered area $\mathrm{R}=200 \times 200 \mu \mathrm{m}^{2}$,

3 . $\mathrm{Cs}^{+}$beam at the energy of $14.5 \mathrm{keV}$, negative ions collected, primary beam current at $200 \mathrm{nA}$, sputtered area $\mathrm{R}=200 \times 200 \mu \mathrm{m}^{2}$,

The SIMS results show, that for the standard measurement of carbon in $\mathrm{GaN}$ as a negative ion $\mathrm{C}^{-}$, the ion yield is enhanced when the cluster of carbon and nitrogen (as a matrix element) $\mathrm{CN}^{-}$is detected. Such cluster delivers 

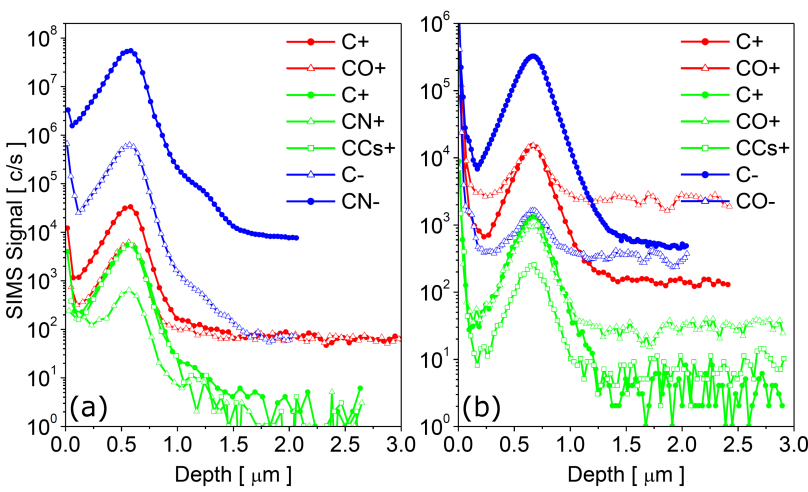

Fig. 5. Depth profiles of carbon implanted into materials, as measured under 3 different $(\mathrm{O} 2(+)$ red, Cs $(+)$ green, Cs $(-)$ blue) measurement condition: (a) $\operatorname{GaN}\left(D=1 \times 10^{16} \mathrm{~cm}^{-2}, E=350 \mathrm{keV}\right)$, (b) ZnO $\left(D=1 \times 10^{16} \mathrm{~cm}^{-2}, E=500 \mathrm{keV}\right)$. The depth profiles of ion signal with the highest ion yield at the same conditions are marked with the full symbols.

the ion yield two order of magnitude higher than single carbon atom (Fig. 5a - blue). In case of carbon detection in $\mathrm{ZnO}$, collecting the cluster of carbon and oxygen (as a matrix element) gives the opposite effect, because the $\mathrm{CO}$ particle has the ion yield two orders of magnitude lower than single carbon atom (Fig. $5 \mathrm{~b}$ - blue).

For the positive secondary ions, the detection of the cluster does not bring the effect of increasing the ion yield. For the GaN sputtered using the oxygen beam, $\mathrm{C}^{+}$ ion has higher ion yield than $\mathrm{CO}^{+}$cluster (Fig. $5 \mathrm{a}-$ red), while for $\mathrm{ZnO}$ material both ion yields are comparable (Fig. 5b - red). For the cesium beam sputtering and positive ion detection, the ion yields of carbon ions and carbon clusters are the lowest of the all measurement conditions, and the detection of single atom ions gives the best results (Fig. 5a, b - green).

Depth profiles of carbon show, that the best carbon detection limit for both $\mathrm{GaN}$ or $\mathrm{ZnO}$ material is obtained using cesium primary beam and detection the negative single atom ions $\mathrm{C}^{-}$(Fig. 6a, b - blue). It is worth noting that in the case of GaN measurement the much higher ion yield at comparable detection limit is obtained for previously mentioned $\mathrm{CN}^{-}$ions.

The literature on research on carbon in GaN includes very few publications on the SIMS measurements. One of the first paper devoted entirely to the conditions of carbon measurement in GaN using this method [105], shows that the $\mathrm{CN}^{-}$molecule achieves the highest ion yield in the material. This is due to the high electron affinity of $\mathrm{CN}$ molecule, amounting to $3.82 \mathrm{eV}[106]$. By measuring the cluster with the ${ }^{13} \mathrm{C}$ carbon isotope, the detection limit at the level of $3 \times 10^{15}$ at $/ \mathrm{cm}^{3}$ was obtained. It results in the detection limit of $2 \times 10^{17} \mathrm{at} / \mathrm{cm}^{3}$ considering the abundance of carbon isotopes. One of the first results of SIMS measurements of GaN:C presented the carbon depth profiles in semi-insulating GaN used for fabrication of high-mobility AlGaN/GaN heterostructures grown by ammonia molecular beam

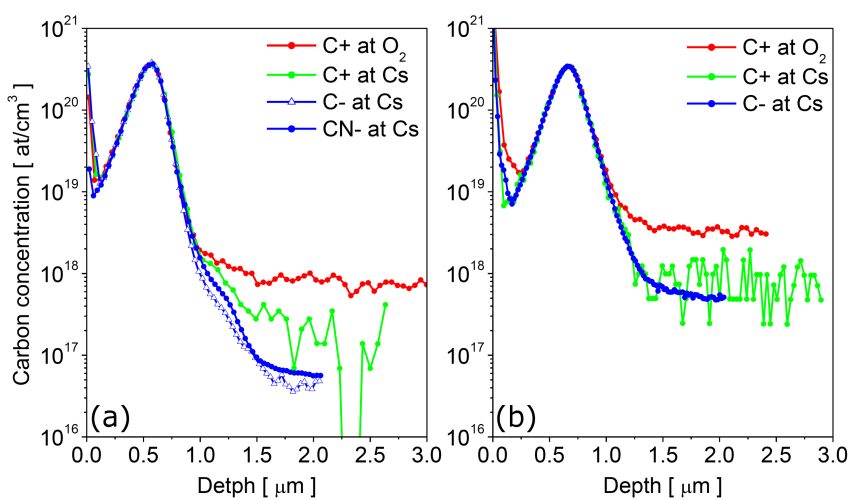

Fig. 6. Carbon depth profiles in concentration values: (a) GaN $\left(D=1 \times 10^{16} \mathrm{~cm}^{-2}, E=350 \mathrm{keV}\right)$, (b) $\mathrm{ZnO}$ $\left(D=1 \times 10^{16} \mathrm{~cm}^{-2}, E=500 \mathrm{keV}\right)$.

epitaxy [82]. In these studies, the measured concentration of carbon in the GaN layers is within the range of $5 \times 10^{17}-10^{19}$ at $/ \mathrm{cm}^{3}$. Using the time of flight (ToF) spectrometer the carbon concentration in intentionally doped cubic GaN grown by MBE method in the range of $10^{18}-10^{20}$ at $/ \mathrm{cm}^{3}$ was determined [92]. Control of residual carbon concentration in MOCVD grown GaN made it possible to evaluate detection limit of the element to the level of $3 \times 10^{16}$ at $/ \mathrm{cm}^{3}$ [93]. Two times lower detection limit was achieved by the Evans Analytical Group (EAG) [107] at the studies of carbon precursors for GaN doping in chemical vapor deposition growth method. The lowest detection limit of carbon in GaN of $10^{15}$ at $/ \mathrm{cm}^{3}$ was obtained by [94], but the measurement conditions were not described. The SIMS measurement of gallium nitride grown by hydride vapor phase epitaxy (HVPE) allow receiving the carbon detection limit at the level of $5 \times 10^{15}$ at $/ \mathrm{cm}^{3}$ [108-110]. Eventually the highly resistive GaN bulk crystals [83] were obtained.

The very first carbon depth profiles in $\mathrm{ZnO}$ were shown in [97]. The compensation properties of carbon in $\mathrm{ZnO}$ and $\mathrm{ZnO}: \mathrm{N}$ layers grown by MOCVD method was studied, providing the depth profiles in the range of $3 \times 10^{4}-4 \times 10^{5} \mathrm{c} / \mathrm{s}$, what for standard SIMS measurement gives the dopant concentration in the range of $10^{19}-10^{21} \mathrm{at} / \mathrm{cm}^{3}$. In the undoped layer grown by magnetron sputtering, the signal as low as $300 \mathrm{c} / \mathrm{s}$ was detected, what results in the detection limit at the level of $10^{17}$ at $/ \mathrm{cm}^{3}$. SIMS measurements were also used to check the possibility of removing carbon from the $\mathrm{ZnO}: \mathrm{Al}$ layers by irradiating samples with UV light [111].

In the $\mathrm{ZnO}$ layers grown by atomic layer deposition (ALD) method it is possible to simultaneously monitor both unintentional hydrogen and carbon. The detection limits of carbon are comparable whether analysis is conducted in positive or negative secondary ion mode (Fig. 6b). Thus, when measuring nanometer thick $\mathrm{ZnO}$ layers, the sufficently low energy primary beam $(\leq 5.5 \mathrm{kV})$ can be used for positive ion detection. This allows to perform the depth profiling with higher depth resolution [69-71]. 


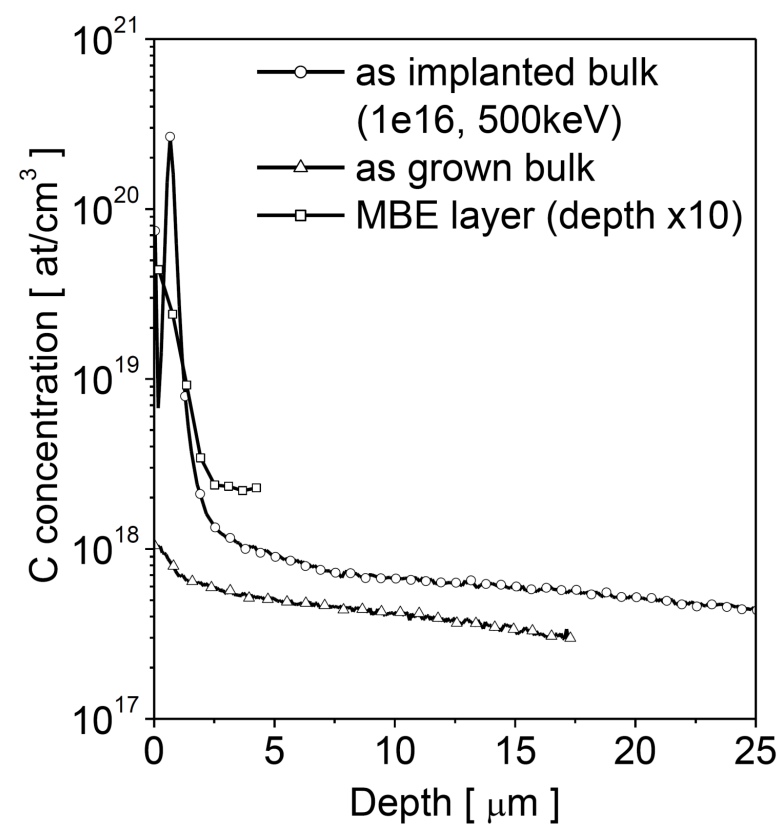

Fig. 7. Carbon depth profiles in C-implanted $\mathrm{ZnO}$ bulk, as grown $\mathrm{ZnO}$ bulk and as grown $\mathrm{ZnO}$ MBE layer.

TABLE II

Isotope RSF's for carbon as measured on CAMECA IMS $6 \mathrm{~F}, \mathrm{Cs}^{+}(14.5 \mathrm{keV})$, neg.

\begin{tabular}{c|c}
\hline \hline $\mathrm{C}$ in GaN in reference to \\
${ }^{69} \mathrm{Ga}^{-}$ & $\begin{array}{c}\mathrm{C} \text { in } \mathrm{ZnO} \text { in reference to } \\
{ }^{64} \mathrm{Zn}_{2}^{16} \mathrm{O}_{2}^{-}\end{array}$ \\
\hline${ }^{12} \mathrm{C}^{-} / 10^{20}$ & ${ }^{12} \mathrm{C}^{-} / 10^{21}$ \\
${ }^{12} \mathrm{C}^{14} \mathrm{~N}^{-} / 10^{18}$ &
\end{tabular}

There is a lack of information in the literature regarding the detection limit of carbon in $\mathrm{ZnO}$. We have measured C-implanted zinc oxide crystal with high density Cs primary beam $\left(\mathrm{I}=300 \mathrm{nA}\right.$, rastered area $\left.50 \times 50 \mu \mathrm{m}^{2}\right)$ to establish this parameter. The results are presented in Fig. 7. For as-implanted sample detection limit at the level of $4 \times 10^{17} \mathrm{at} / \mathrm{cm}^{3}$ was achieved. The decrease of carbon signal along the depth result from the vacuum improvement as more $\mathrm{ZnO}$ material is sputtered. Subsequent measurement of as grown commercial bulk sample, confirms further decrease of carbon signal with time of sputtering. Applying such procedure our ultimate detection limit of $2 \times 10^{17}$ at $/ \mathrm{cm}^{3}$ seems to be the lowest amid any data reported in literature. From Fig. 7 it can be concluded that residual carbon content in MBE grown material reveals one order of magnitude higher carbon concentration relative to bulk.

In conclusion, carbon is an element that is quite effectively detected in the SIMS measurement. Moreover, its detectability increases in the nitrogen-contained materials, due to the high electron affinity of CN molecules.

Table II lists the isotope RSF's for carbon as measured with CAMECA IMS6F using $\mathrm{Cs}^{+}$primary beam at the energy of $14.5 \mathrm{keV}$ in GaN or $\mathrm{ZnO}$.

\section{Nitrogen}

Nitrogen is the main (over 78\%) air component, therefore it has a significant contribution to the contamination in all crystal growth devices operating in a vacuum or at atmospheric pressure. Nitrogen in the atmosphere occurs in $\mathrm{N}_{2}$ diatomic molecules similar to oxygen. On the other hand, unlike $\mathrm{C}$ and $\mathrm{O}$ elements, it is the least reactive element because the bonding energy of triple bond nitrogen atoms is almost $10 \mathrm{eV}$. Thus, the amount of energy needed to break the $\mathrm{N}_{2}$ molecule makes it difficult in incorporating nitrogen in any materials because as a diatomic molecule it is much less mobile in the crystal lattice. On the other hand, such properties make the nitrogen doping of semiconductors as $\mathrm{SiC}$ or $\mathrm{ZnO}$ ineffective and requiring elevated temperatures to obtain atomic nitrogen.

\subsection{Nitrogen properties in $\mathrm{ZnO}$}

The position of nitrogen and oxygen in the Periodic Table, would suggest that $\mathrm{N}$ is the ideal candidate for an acceptor doping of $\mathrm{ZnO}$. Such possibility indeed was demonstrated by Kobayashi in 1983 [112]. However, despite many efforts, a stable and high hole concentration in nitrogen doped $\mathrm{ZnO}$ material was not achieved so far. Even with a dopant concentration as high as $10^{19} \mathrm{at} / \mathrm{cm}^{3}$ in the layer grown by molecular beam epitaxy, the material did not exhibit acceptor conductivity [113]. This was ascribe to a large amount of carrier compensating defects. The hole concentration of $9 \times 10^{16} \mathrm{~cm}^{-3}$ at the nitrogen concentration of $10^{18}-10^{19}$ at $/ \mathrm{cm}^{3}$ in homoepitaxial layers grown by MBE [114] was achieved. Less known Metalorganic Molecular-Beam Epitaxy (MOMBE) method was used to grow $\mathrm{ZnO}: \mathrm{N}$ layers with the nitrogen concentration of $10^{20}$ at $/ \mathrm{cm}^{3}$ [115]. Acceptor concentration of $5 \times 10^{16} \mathrm{~cm}^{-3}$ using mercury probe capacitancevoltage measurement was demonstrated, in spite of a high hydrogen concentration over $10^{21}$ at $/ \mathrm{cm}^{3}$. The exceeding of certain nitrogen concentration in the layers grown by $\mathrm{MBE}$ method results in the conversion of $p$-type into high-resistive material [116]. A large redshift in the donor-acceptor pair emission was observed in photoluminescence measurements, which was explained by a large compensation of $\mathrm{N}_{\mathrm{O}}$ acceptors by $\left(\mathrm{N}_{2}\right)_{\mathrm{O}}$ donors. Comparison of the influence of nitrogen sources on $\mathrm{N}$ doping in the plasma assisted molecular beam epitaxy (PAMBE) method was given in [117]. With NO as a nitrogen precursor the electrical activity of doping was found superior to the $\mathrm{N}_{2}$. Using this precursor for $\mathrm{ZnO}: \mathrm{N}$ growth the carrier concentration of $1.25 \times 10^{18} \mathrm{~cm}^{-3}$ was achieved with the mobility of $0.5 \mathrm{~cm}^{2} / \mathrm{Vs}$, while $\mathrm{N}_{2}$ precursor led to the formation of the $n$-type layer.

The NO precursor was also used for the $\mathrm{ZnO}: \mathrm{N} / \mathrm{Al}_{2} \mathrm{O}_{3}$ layers growth [118], but only in one out of five layers the acceptor conductance with the carrier concentration of $2.2 \times 10^{16} \mathrm{~cm}^{-3}$ with equally low hole mobility of $1.3 \mathrm{~cm}^{2} / \mathrm{Vs}$ was exhibited. The MBE method was also used to produce $p-n$ junction with the $\mathrm{ZnO}: \mathrm{N}$ as $p$-type 
and GaN as $n$-type layer [119]. Nitrogen concentration in $\mathrm{ZnO}$ of $10^{20} \mathrm{at} / \mathrm{cm}^{3}$ allowed to achieve $10^{17} \mathrm{at} / \mathrm{cm}^{3}$ hole concentration at the mobility of $15 \mathrm{~cm}^{2} / \mathrm{Vs}$. Zinc oxide based $p-n$ junction with nitrogen as acceptor was also produced by homoepitaxial growth using ALD method [120]. Hole concentration of $1.5 \times 10^{17} \mathrm{~cm}^{-3}$ at mobility $6.1 \mathrm{~cm}^{2} / \mathrm{Vs}$ was provided from dopant concentration of $>10^{21} \mathrm{at} / \mathrm{cm}^{3}$. A higher concentration of acceptors $\left(9 \times 10^{17} \mathrm{~cm}^{-3}\right)$ was also achieved by $\mathrm{N}$ and $\mathrm{Al}$ codopig [121].

The early attempts of $\mathrm{ZnO}$ doping with nitrogen using MOCVD method resulted in the carrier concentration at a level of $10^{16}$ at $/ \mathrm{cm}^{3}[122]$. With the nitrogen concentration of $10^{21}$ at $/ \mathrm{cm}^{3}$, only the compensation of $n$-type material was obtained in [123]. Furthermore, $p$-type layers with the hole concentration of $10^{17} \mathrm{~cm}^{-3}$ were achieved by the nitrogen diffusion from the ambient atmosphere. It was also noticed that the oxygen-rich atmosphere during annealing, favors the reduction of compensating donors in the material. The first layers showing the acceptor conductivity grown using the MOCVD method was reported by the authors of [124]. Total donor compensation and conversion to the $p$-type conductivity occurred at $2 \%$ nitrogen content, which corresponds to a concentration of $1.7 \times 10^{21} \mathrm{at} / \mathrm{cm}^{3}$. Eventually, the achieving of $3 \%$ nitrogen content in the $\mathrm{ZnO}$ layers produced the carrier concentration at the level of $10^{16} \mathrm{~cm}^{-3}$. To receive even higher carrier concentration the post-grown activation annealing at the temperature of $700{ }^{\circ} \mathrm{C}$ was applied [125]. It allowed to achieve the hole concentration of $8.3 \times 10^{17} \mathrm{~cm}^{-3}$, however at very low carrier mobility $4.3 \mathrm{~cm}^{2} / \mathrm{Vs}$.

Ion implantation is another non-equlibrium method employed to incorporate the dopant species. One of the first reports on this method was nitrogen implantation into layers grown by magnetron sputtering. Only in the case of implantation doses above $10^{15}$ at $/ \mathrm{cm}^{2}$ and subsequent annealing at $600^{\circ} \mathrm{C}$, the hole conductivity was achieved. Using lower implantation doses and subsequent annealing at the temperatures of $850^{\circ} \mathrm{C}$ under $\mathrm{N}_{2}$ ambient pressure, the carrier concentrations of the range $5 \times 10^{16}-7.3 \times 10^{17}$ at $/ \mathrm{cm}^{3}$ at the mobility of $2.5-6 \mathrm{~cm}^{2} / \mathrm{Vs}$ was demonstrated. Such a result is comparable with those obtained by the epitaxial growth [126]. Increasing the implantation dose above $10^{16}$ at $/ \mathrm{cm}^{2}$ leads to the creation of donor defects so conversion to the $p$-type material is virtually impossible and electron concentrations reach values $>6 \times 10^{22} \mathrm{~cm}^{-3}$ [127]. High acceptor concentration was achieved using the implantation at the temperatures in the range of $300-460{ }^{\circ} \mathrm{C}[128]$. Nitrogen was implanted into $\mathrm{ZnO}$ layers grown by pulsed-laser deposition (PLD) method on the sapphire substrate. Implantation dose of $3 \times 10^{14}-1.2 \times 10^{15}$ at $/ \mathrm{cm}^{2}$ produced the hole concentrations in the range of $2.4 \times 10^{16}-5.2 \times 10^{17} \mathrm{~cm}^{-3}$ with the mobility of $0.7-3.7 \mathrm{~cm}^{2} / \mathrm{Vs}$, at the temperatures of 380 or $460^{\circ} \mathrm{C}$.

The highest acceptor concentrations in the $\mathrm{ZnO}: \mathrm{N}$ layers were obtained by unordinary growth methods.
The carrier concentrations in the range of $3-6 \times 10^{18} \mathrm{~cm}^{-3}$ was reached by pulsed laser reactive deposition (PRLD) method using zinc target in $\mathrm{N}_{2} \mathrm{O}$ plasma [129]. Unfortunately, the resultant layers exhibited very low carrier mobility of $0.1-0.4 \mathrm{~cm}^{2} / \mathrm{Vs}$. Higher hole concentration was observed in $\mathrm{ZnO}$ layers deposited by ultrasonic spray pyrolysis (USP) on the silicon substrate [130]. The hole concentration of $8.6 \times 10^{18} \mathrm{~cm}^{-3}$ at carrier mobility of $24.1 \mathrm{~cm}^{2} / \mathrm{Vs}$ was reported. A comparable level of acceptor concentration was obtained by diffusion of nitrogen into $\mathrm{ZnO}$ layers grown by the magnetron sputtering process [131]. The source of nitrogen was the WN tungsten nitride layer deposited on the glass substrate subsequently overgrown by a $\mathrm{ZnO}$ layer. Annealing at the temperatures of $200-600^{\circ} \mathrm{C}$ caused the nitrogen diffusion from the nitride layer into the semiconductor. The hole concentration at the level of $3.7 \times 10^{18} \mathrm{~cm}^{-3}$ with the carrier mobility of $1.35 \mathrm{~cm}^{2} / \mathrm{Vs}$ was showed by the hall method measurement. Similar doping method was used in [132], where the $\mathrm{ZnO}$ layers were grown by MOCVD method on the indium nitride $(\mathrm{InN})$ layer. After annealing at the temperature of $850^{\circ} \mathrm{C}$, the presence of acceptors was confirmed by photoluminescence method. The magnetron sputtering method was used to compare the nitrogen incorporation efficiency into $\mathrm{ZnO}$ layer grown on three different substrates: silicon, quartz or aluminum [133]. Dopant activation was conducted by the one-hour annealing at the temperature of $500^{\circ} \mathrm{C}$. The hole concentration of $2 \times 10^{17} \mathrm{~cm}^{-3}$ was achieved, at the carrier mobility of $\sim 58 \mathrm{~cm}^{2} / \mathrm{Vs}$ for the material grown on the silicon substrate. Moreover, the $p$-type conductivity remained stable for a long time only for the post-grown activated samples. Sol-gel spin coating method was also used for producing the $\mathrm{ZnO}: \mathrm{N}$ layer [134]. The hole concentration of $10^{18} \mathrm{~cm}^{-3}$, as well as carrier mobility of $1.3 \mathrm{~cm}^{2} / \mathrm{Vs}$ were comparable with the parameters of samples obtained by the previous method.

Innovative method for achieving the $p$-type $\mathrm{ZnO}: \mathrm{N}$ layer was proposed by the authors of [135]. The oxidation of $\mathrm{Zn}_{3} \mathrm{~N}_{2}$ compound grown by plasma-enhanced chemical vapor deposition at the temperature of $700^{\circ} \mathrm{C}$ produced the zinc oxide layer with the nitrogen and hole concentration of $10^{21}$ at $/ \mathrm{cm}^{3}$ and $4.2 \times 10^{17} \mathrm{~cm}^{-3}$, respectively. Similar results were obtained by oxidation of $\mathrm{Zn}_{3} \mathrm{~N}_{2}$ layers grown by magnetron sputtering process [136, 137] producing the nitrogen concentration of $4 \times 10^{19} \mathrm{at} / \mathrm{cm}^{3}$ at the hole concentration of $10^{17} \mathrm{~cm}^{-3}$ and carrier mobility of $10 \mathrm{~cm}^{2} / \mathrm{Vs}$. However, the highest hole concentration of nitrogen acceptors in $\mathrm{ZnO}$ was achieved by oxidation of ZnTe:N layers grown by MBE method on GaAs substrate [138]. The hole concentration amount to $2.2 \times 10^{19} \mathrm{~cm}^{-3}$ at the carrier mobility $11 \mathrm{~cm}^{2} / \mathrm{Vs}$. The oxidation of homoepitaxially grown ZnTe:N layer brought the hole concentration two order of magnitude lower. Very interesting research was conducted by authors of [139], which have received the $p$-type layers $\left(2.7 \times 10^{16} \mathrm{~cm}^{-3}\right)$ by oxidizing of $\mathrm{ZnON}$ layers grown by 
plasma enhanced chemical vapor deposition (PE-CVD) method. Keeping samples in darkness leads to maintaining the acceptor concentration at a constant level for a long period (the results for 15 months was presented in the paper). Samples exposition to electromagnetic radiation of energy $2.72 \mathrm{eV}(\lambda=456 \mathrm{~nm}$, blue light) led to electron conductivity, whereas irradiation at lower energy led only to decreasing of acceptor concentration. The cut off the samples from the light resulted in the relaxation process and restoration of acceptor conductivity.

One of the main obstacles in obtaining a stable and high acceptor concentration using the nitrogen as a dopant in $\mathrm{ZnO}$ is the carrier compensation by point defects. The possible causes of compensation were pointed in the first theoretical work on nitrogen doped $\mathrm{ZnO}$ [140]. At the low nitrogen concentration the oxygen vacancy $\mathrm{V}_{\mathrm{O}}$, while at high nitrogen concentration the $\mathrm{Zn}$ antisite $\mathrm{Zn}_{\mathrm{O}}$ as the main compensating defects were suggested. Moreover, when doping takes place using active nitrogen plasma, the predominant compensation defect is the nitrogen molecule at the oxygen site $\left(\mathrm{N}_{2}\right)_{\mathrm{O}}$ and the $\mathrm{N}_{\mathrm{O}}-\mathrm{N}_{2}$ complex. The comparison of doping using $\mathrm{N}_{2}, \mathrm{~N}_{2} \mathrm{O}$, NO or $\mathrm{NO}_{2}$ as precursors was described in [141]. According to these calculations, $\mathrm{NO}$ and $\mathrm{NO}_{2}$ molecules exhibit the highest efficiency of incorporation into $\mathrm{ZnO}$ crystal. The problems in $\mathrm{ZnO} p$-type doping by IA or $\mathrm{V}$ group elements were discussed in [142]. The authors stated that: (i) the formation of the AX centers is not the reason for p-type doping hampering in $\mathrm{ZnO}$, except for $\mathrm{P}$ and $\mathrm{As}$, (ii) $\mathrm{N}$ has the smallest ionization energy, but only a small percentage of the $\mathrm{N}$ dopant remains ionized in the crystal, iii) $\mathrm{N}$ is the best elemental dopant source for $p$-type $\mathrm{ZnO}$ as it does not form the $\mathrm{N}_{\mathrm{Zn}}$ antisite, while the $\mathrm{AX}$ center related to nitrogen is is thought to be metastable.

Calculations from the first principles were brought further tips on the possibility of $\mathrm{ZnO}$ nitrogen doping [143]. The high formation enthalpy of $\mathrm{N}_{\mathrm{O}}$ defect at the molecular nitrogen $\mathrm{N}_{2}$ doping was shown. On the other hand, the use of a NO molecule leads to enthalpy decreasing, resulting in locally unstable $\mathrm{N}-\mathrm{Zn}$ bond and varying over time by either attracting a second nitrogen atom and forming a donor defect $\left(\mathrm{N}_{2}\right)_{\mathrm{O}}$ or diffusion in the crystal lattice and leaving an oxygen vacancy $\mathrm{V}_{\mathrm{O}}$, also being a donor. Ga codoping as substitutional nitrogen $\mathrm{N}_{\mathrm{O}}$ stabilizing was also proposed. The first principles calculation was also used [144], to propose a model indicating $10^{16} \mathrm{~cm}^{-3}$ as the highest $\mathrm{N}_{\mathrm{O}}$ acceptor concentration at equilibrium conditions owing to the balance between the $\mathrm{O}$ and $\mathrm{Zn}$ chemical potentials. In the case of doping under a high zinc chemical potential, the high concentration of nitrogen located on $\mathrm{N}_{\mathrm{O}}$ site was observed, while under the high oxygen chemical potential a low concentration of compensating donors was demonstrated. Appropriate non-equilibrium conditions balancing both potentials should lead to acceptor concentration at the level of $10^{17}-10^{19} \mathrm{~cm}^{-3}$. A radical change in the description of the nitrogen properties as an acceptor in $\mathrm{ZnO}$ was shown by the authors of [145]. Based on calculations using a density functional theory containing hybrid functionals, the level of transition $(0 /-)$ of nitrogen in $\mathrm{ZnO}$, which determines the ionization energy level of the acceptor, was calculated as $1.3 \mathrm{eV}$ above the valence band. The dopant exhibits the formation energy of $2.2 \mathrm{eV}$ decreasing with the Fermi level increase. The deep state of the $\mathrm{N}_{\mathrm{O}}$ acceptor in zinc oxide was also confirmed by the subsequent calculations included in the work [146]. Local density approximation with Hubbard U-corrections $(\mathrm{LDA}+\mathrm{U})$ method was used to confirm the deep state of $\mathrm{N}_{2}$ molecule on oxygen site $\left(\mathrm{N}_{2}\right)_{\mathrm{O}}$. The $\mathrm{N}_{2}$ molecule on zinc site $\left(\mathrm{N}_{2}\right)_{\mathrm{Zn}}$ as shallow acceptor dopant was proposed. The results were compared with the electron paramagnetic resonance (EPR) measurement [147].

In conclusion, research on the nitrogen doping of zinc oxide has not resulted in production of high quality $p-n$ junction. The first experimental results showed the possibility of creating $p$-type layers but with low carrier concentration, while later theoretical results suggest that nitrogen is a deep acceptor in $\mathrm{ZnO}$.

\subsection{Nitrogen properties in $\mathrm{SiC}$}

In the crystal lattice of group IV semiconductors (i.e., $\mathrm{Si}$ or $\mathrm{Ge}$ ) the atom is bonded with 4 neighboring atoms in the tetrahedral structure. Thus, it is evident that for this kind of semiconductor, the donor dopants are the group $\mathrm{V}$ elements, which have a free valence electron after filling the entire tetrahedral bond. The same applies to silicon carbide $\mathrm{SiC}$, a semiconductor contained two group IV elements, for which the natural donor is nitrogen. The first studies on the nitrogen site in $\mathrm{SiC}$ crystal lattice [148] using the electron spin resonance (ESR) showed, that it substitutes carbon in three non-equivalent places in the lattice $\left(h, k_{1}\right.$ and $\left.k_{2}\right)$ with an equal probability for each site. Subsequently, the nitrogen diffusion coefficients in $\mathrm{SiC}$ in the temperature range of $2000-2700^{\circ} \mathrm{C}$ were determined [149] with the activation energy of the range 7.6-9.35 eV and pre-exponential factor $D_{O}$ of the range $4.6-8.7 \times 10^{4} \mathrm{~cm}^{2} / \mathrm{s}$. Highly polarized absorption bands in visible and near infrared light in strongly nitrogen-doped silicon carbide of $4 \mathrm{H}, 6 \mathrm{H}, 8 \mathrm{H}$ or $15 \mathrm{R}$ polytypes were observed by Biedermann [150]. They were interpreted as a direct transitions from the lowest state below the conduction band to higher states in the conduction band. The measurement of $27 \mathrm{R}, 33 \mathrm{R}$ and $21 \mathrm{R}$ polytypes was conducted by Dubrovskii [151]. The dependence of nitrogen dopant energy levels on the atom position in crystal lattice based on photoluminescence measurements was shown by Ikeda [152]. It was evidenced that the level connected with the hexagonal site has lower ionization energy than the level associated with the cubic site.

Nitrogen donor ionization energy in $6 \mathrm{H}-\mathrm{SiC}$ crystals for the hexagonal configuration $h$ and for cubic configuration $k_{1}$ and $k_{2}$ were calculated by Hall effect measurement and amounted $85.5 \mathrm{meV}$ and $125 \mathrm{meV}$ respectively [153]. The Hall effect measurement for $4 \mathrm{H}-\mathrm{SiC}$ polytype was provided by the same authors in [154] exhibiting two equivalent positions $h$ and $k$ of the nitrogen atom with 
the ionization energy of $52.1 \mathrm{meV}$ and $91.8 \mathrm{meV}$, respectively. Two lattice sites of nitrogen $\mathrm{N}_{\mathrm{C}}$ as a donor in $\mathrm{SiC}$ were also found in $3 \mathrm{C}$ polytype [155].

In parallel to the research aimed at determining the activation energy of nitrogen, the solubility parameters of nitrogen in $\mathrm{SiC}$ were addressed as well. The very first result was published by Lilov [156]. In the crystals grown from vapor phase by the sublimation method in a temperature interval $1900-2200^{\circ} \mathrm{C}$, the nitrogen concentration of $>10^{19} \mathrm{at} / \mathrm{cm}^{3}$ was reported. The $\mathrm{N}_{\mathrm{C}}$ defect formation energy of $-1.41 \mathrm{eV}(32.6 \mathrm{kcal} / \mathrm{mol})$ was determined from the Arrhenius plot. Negative energy means that the nitrogen solubility decreases with increasing temperature. The exponential dependence of nitrogen concentration on the $\mathrm{N}_{2}$ partial pressure in the growth chamber was also revealed. The negative formation energy of nitrogen in $\mathrm{SiC}$ lattice was confirmed in [157], where the properties of nitrogen doped $\left(10^{19}-4 \times 10^{20} \mathrm{at} / \mathrm{cm}^{3}\right)$ $\mathrm{SiC}$ grown by physical vapor transport (PVT) method were described. The concentration of nitrogen in this method increased accordingly to the square root of $\mathrm{N}_{2}$ spartial pressure. Impurity incorporation kinetics during modified-Lely method growth of nitrogen doped $\mathrm{SiC}$ $\left(1-8 \times 10^{19} \mathrm{at} / \mathrm{cm}^{3}\right)$ was discussed in [158]. $\mathrm{N}_{2}$ partial pressure dependent concentration described by Langmuir isotherm was confirmed, with dynamics higher for $6 \mathrm{H}$ than for $4 \mathrm{H}$ polytype. In addition, the incorporation efficiency was found higher in the C-side direction of crystal growth. The difference in the nitrogen concentration depending on the growth direction was also predicted by theoretical calculations [159]. In subsequent studies, a strong dependence of the nitrogen incorporation on the chemical potential was also demonstrated. The donor concentration increase with the increasing of $\mathrm{Si}$ chemical potential $(\mathrm{Si} / \mathrm{C}$ ratio) was shown by the authors of $[160,161]$. The site-competition epitaxy mechanism where the nitrogen and carbon atoms compete for a site in the carbon sublattice were proposed. The same is valid for higher nitrogen concentrations [162, 163]. The difference may arise from the fact that the calculations were performed for the temperatures of $2000^{\circ} \mathrm{C}$ and higher. Moreover, the saturation of nitrogen electrical activity was demonstrated for $\mathrm{N}_{\mathrm{C}}$ position. It forms complexes with the vacancies over the $\mathrm{N}$ concentration of $\sim 3 \times 10^{19}$ at $/ \mathrm{cm}^{3}$ at high carbon chemical potential and over the $\mathrm{N}$ concentration of $10^{20}$ at $/ \mathrm{cm}^{3}$ for the high silicon chemical potential. According to the results presented in this work, the solubility increases at the temperatures in the range of $2000-2500{ }^{\circ} \mathrm{C}$, which contradics earlier reports.

For nitrogen doping of silicon carbide two methods are most commonly used: implantation and chemical vapor deposition (CVD). The first report on $\mathrm{N}$ implanted $\mathrm{SiC}$ was published by Addamiano et. al. [164]. SiC samples were implanted with $\mathrm{N}, \mathrm{B}$ or $\mathrm{Al}$ at the energy of $60 \mathrm{keV}$ to the dose of $7.5 \times 10^{12}-2.5 \times 10^{17}$ at $/ \mathrm{cm}^{2}$ and subsequently activated at temperatures of $800-1400^{\circ} \mathrm{C}$. In further studies the nitrogen implanted silicon carbide with the wide range of the energies and doses was used for the formation of $p-n$ junction $[165,166]$, determination of diffusion coefficients [167, 168], the electric activation of nitrogen [169-173] and the dopant energy levels in the band gap [174].

The first attempts of epitaxial growth of $\mathrm{SiC}$ layers were carried out by Campbel [175] using thermal reduction technique (TRT), whereas the first epitaxial growth of SiC layer from the gas phase was described Minagawa [176]. The CVD method consolidated its position as a high-tech technology method for the production of $\mathrm{SiC}$ epitaxial layers, allowing the doping the semiconductor in a controlled manner [177-179]. Similarly to the implantation method the CVD epitaxial layers allowed to determine the electrical properties of nitrogen dopant [180, 181], donor energy level in the band gap [182, 183] or the Hall scattering factor [184].

SIMS method was widely used for characterization of $\mathrm{SiC}$ bulk crystals $[185,186]$. The influence of nitrogen on growth stability of $4 \mathrm{H}-\mathrm{SiC}$ polytype was given in [187]. At the concentration of $10^{19}$ at $/ \mathrm{cm}^{3}$ the homogeneity of the polytype in the crystal was estimated to $95 \%$. With lower amount of nitrogen in $6 \mathrm{H}$ and $15 \mathrm{R}$ polytype inclusions were identified.

In conclusion, the technology of nitrogen doping of silicon carbide is fairly well established in the semiconductor industry (especially for the production of highpower devices) with adequate control of dopant electrical activity [188].

\subsection{SIMS measurement of nitrogen}

It seems that nitrogen is one of the most challenging element to be measured by a SIMS technique. This is mainly due to its high ionization potential $\sim 14.5 \mathrm{eV}$ (very low $\mathrm{N}^{+}$ion yield), one of the lowest value of electron affinity $\sim 0.073 \mathrm{eV}$ (very low $\mathrm{N}^{-}$ion yield) and high negative enthalpy of formation of $\mathrm{N}_{2}$. Nevertheless, the concentration of nitrogen in semiconductors can be measured with very low detection limit, by taking advantage of its high affinity to form cluster with elements such a C, O or Si.

Figures 8 and 9 show the depth profiles of nitrogen implanted into $\mathrm{ZnO}$ or $\mathrm{SiC}$ under three measurement conditions:

1. $\mathrm{O}_{2}^{+}$beam at the energy of $8 \mathrm{keV}$, positive ions collected, primary beam current at $800 \mathrm{nA}$, sputtered area $R=200 \times 200 \mu \mathrm{m}^{2}$

2. $\mathrm{Cs}^{+}$beam at the energy of $5.5 \mathrm{keV}$, positive ions collected, primary beam current at $200 \mathrm{nA}$, sputtered area $R=200 \times 200 \mu \mathrm{m}^{2}$,

3 . $\mathrm{Cs}^{+}$beam at the energy of $14.5 \mathrm{keV}$, negative ions collected, primary beam current at $200 \mathrm{nA}$, sputtered area $R=200 \times 200 \mu \mathrm{m}^{2}$,

It is worth noting that both plots contain only one depth profile of atomic nitrogen each and they correspond to the conditions when the material is sputtered using the oxygen beam. Oxygen rich conditions are favorable 


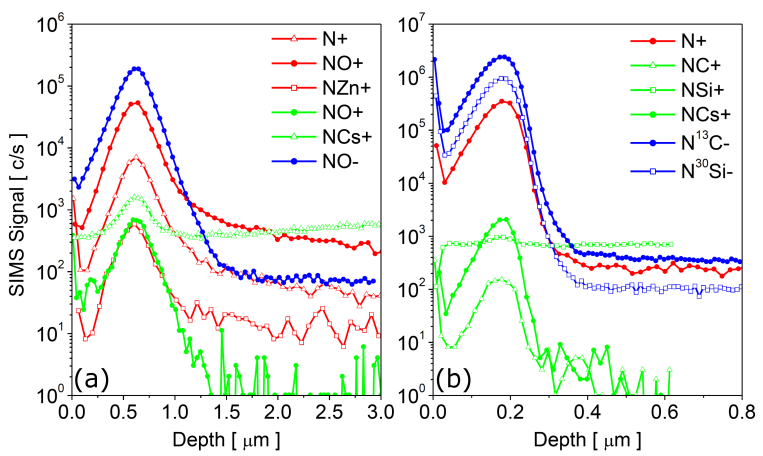

Fig. 8. Depth profiles of nitrogen implanted into $\mathrm{ZnO}$ or $\mathrm{SiC}$ materials, as measured under 3 different measurement condition $(\mathrm{O} 2(+)$ red, $\mathrm{Cs}(+)$ green, Cs $(-)$ blue): (a) $\mathrm{ZnO}\left(D=8.6 \times 10^{15} \mathrm{~cm}^{-2}, E=500 \mathrm{keV}\right)$ (b) $\mathrm{SiC}\left(D=2 \times 10^{16} \mathrm{~cm}^{-2}, E=100 \mathrm{keV}\right)$. The depth profiles of ion signals with the highest ion yield at the same conditions are marked with the full symbols.

for the high ion yield of atomic nitrogen. This is due to the high electron affinity of oxygen and positive entalpy of NO molecule. Oxygen enhancement occurs as a result of nitrogen-oxygen bonds in an oxygen rich zone. As bonds are broken in the ion emission process, the oxygen becomes negatively charged because its high electron affinity favors electron capture leaving the nitrogen atom positively charged. For the same reason, the oxygen beam is used to measure electropositive elements, enabling their high ionization yield. Measurement of atomic nitrogen in $\mathrm{SiC}$ encounters yet another difficulty, namely overlapping signals, because the nitrogen signal ${ }^{14} \mathrm{~N}^{+}(\mathrm{M} / \mathrm{q}=14.003)$ is overlapped by the ${ }^{28} \mathrm{Si}^{2+}(\mathrm{M} / \mathrm{q}=13.9865)$ signal. For this reason, the measurement of atomic nitrogen in $\mathrm{SiC}$ requires sufficient mass resolution $(R>700)$.

The bombardment with cesium beam does not allow effective measurement of atomic nitrogen both for the detection of negative as well as positive ions. In both cases the nitrogen concentration in the material $<10^{21} \mathrm{at} / \mathrm{cm}^{3}$ results in atomic nitrogen ion signal placed below the background level. The relatively lower electron affinity of cesium atom compared to oxygen, does not lead to electron capture from nitrogen atom and high enough $\mathrm{N}^{+}$ion yield. In such cases, clusters containing nitrogen atom are used to nitrogen detection. For $\mathrm{ZnO}$ material $\mathrm{N}-\mathrm{O}$ or $\mathrm{N}-\mathrm{Cs}$, while for $\mathrm{SiC}$ material $\mathrm{N}-\mathrm{C}, \mathrm{N}-\mathrm{Si}$ or $\mathrm{N}-\mathrm{Cs}$ are collected (Fig. 8a, b). The $\mathrm{N}-\mathrm{C}$ molecule exhibits a high $\sim 4 \mathrm{eV}$ electron affinity, as mentioned in the carbon section, while for the $\mathrm{N}-\mathrm{O}$ molecule, this parameter is several times lower (electron affinity in the range of $0.02-0.8 \mathrm{eV}$ was reported [189-191]). In the case of NO molecule, high ion yield can be related to the high electron affinity to atomic oxygen and high reactivity of both elements.

A significant ion yield was found also for clusters of the measured element with the primary beam Cs atom. This is because of the low ionization potential of the cesium atom. Therefore the measurement of $\mathrm{MCs}^{+}$cluster is often used in the SIMS method. This method can not be

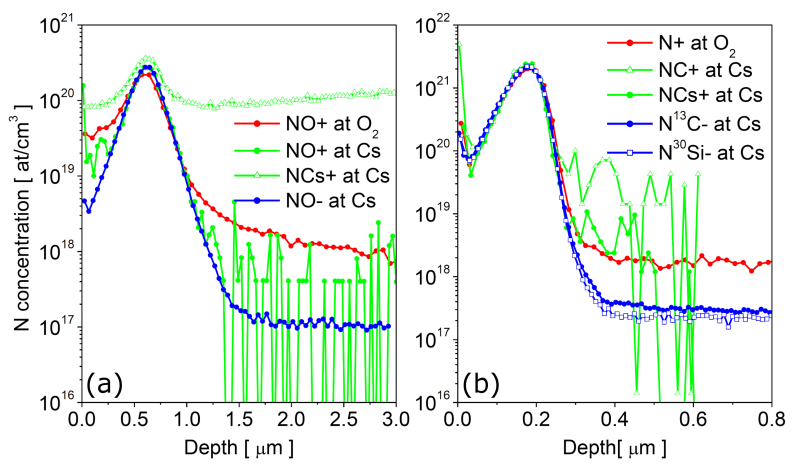

Fig. 9. Nitrogen depth profiles in concentration scale: (a) $\mathrm{ZnO}\left(D=8.6 \times 10^{15} \mathrm{~cm}^{-2}, E=500 \mathrm{keV}\right)$, (b) $\mathrm{SiC}$ $\left(D=2 \times 10^{16} \mathrm{~cm}^{-2}, E=100 \mathrm{keV}\right)$.

used in the case of $\mathrm{ZnO}$ measurement where the signal of NCs cluster mass 147 is overlapped by $\mathrm{Zn}_{2} \mathrm{O}$ cluster with comparable high ion signal (Fig. 8a - green triangles).

More mass overlapping issues occur during the nitrogen measurement in $\mathrm{SiC}$. Detection of $\mathrm{N}-\mathrm{C}$ $(M / q=26 \mathrm{amu})$ cluster is permanently associated with an impassable detection limit resulting from the signal of molecule ${ }^{13} \mathrm{C}_{2}(M / q=26 \mathrm{amu})$. To overcome the ${ }^{13} \mathrm{C}_{2}$ background, the isotope cluster $\mathrm{N}-{ }^{13} \mathrm{C}(M / q=27 \mathrm{amu})$ is taken for the measurement of nitrogen species but it downgrades the SIMS signal. In addition, such trick is ineffective in $\mathrm{Al}(M / q=27 \mathrm{amu})$ doped material [192]. Similar detection limit occurs during the N-Si $(\mathrm{M} / \mathrm{q}=42 \mathrm{amu})$ measurement, which for silicon carbide would have the same $\mathrm{M} / \mathrm{q}$ value as the molecule $\mathrm{Si}_{3}^{2-}$. Similar to the previous issue, again the isotope cluster $\mathrm{N}-{ }^{30} \mathrm{Si}$ (Fig. $8 \mathrm{~b}$ - blue rectangular) is taking into account, but interference may appear with O-Si cluster when analyzing materials containing high oxygen concentration.

The depth profiles in the absolute scale show, that despite low nitrogen ion yield, the detection limit can be comparable to other elements when $\mathrm{N}$-contained clusters are detected. That's why for measuring nitrogen simultaneously with the electropositive elements in $\mathrm{ZnO}$ using an oxygen beam, the $\mathrm{NO}^{+}$cluster is preferred. However, in the case of $\mathrm{SiC}$ material atomic nitrogen $\mathrm{N}^{+}$is chosen.

At the high nitrogen concentration in $\mathrm{ZnO}$ similar detection limit is achieved using the cesium primary beam and $\mathrm{NCs}^{+}$ions detection $[75,193-197]$. These conditions are effective for thin film measurement with low primary beam energy and heavy primary beam ions assuring better depth resolution. The detection limit below $10^{18} \mathrm{at} / \mathrm{cm}^{3}$ is possible to obtain. For the best detection limit of nitrogen the cesium primary beam is used and cluster $\mathrm{NO}^{-}[119,137,138]$ for $\mathrm{ZnO}$ as well as $\mathrm{N}^{13} \mathrm{C}^{-}$or $\mathrm{N}^{30} \mathrm{Si}^{-}$for $\mathrm{SiC}[185,198-200]$ are detected. In the case of nitrogen in silicon carbide, two equivalent molecules in terms of ion yield (Fig. $8 \mathrm{~b}$ - blue) and the detection limit (Fig. 9b - blue) are available. It allows to choose the proper one depending on $\mathrm{Al}$ doping condition or $\mathrm{O}$ impurity in the material. 


\section{TABLE III}

Isotope RSF's for nitrogen as measured on CAMECA IMS $6 \mathrm{~F}, \mathrm{Cs}^{+}(14.5 \mathrm{keV})$, neg.

\begin{tabular}{c|c}
\hline \hline $\begin{array}{c}\mathrm{N} \text { in } \mathrm{ZnO} \text { in reference to } \\
{ }^{64} \mathrm{Zn}_{2}^{16} \mathrm{O}_{2}^{-}\end{array}$ & $\begin{array}{c}\mathrm{N} \text { in } \mathrm{SiC} \text { in reference to } \\
{ }^{30} \mathrm{Si}_{2}^{-}\end{array}$ \\
\hline${ }^{12} \mathrm{C}^{16} \mathrm{O}^{-} / 1.5 \times 10^{21}$ & ${ }^{14} \mathrm{~N}^{13} \mathrm{C}^{-} / 5 \times 10^{21}$ \\
& ${ }^{14} \mathrm{~N}^{30} \mathrm{Si}-/ 2 \times 10^{21}$
\end{tabular}

Concentration depth profiles of nitrogen measured by the SIMS method was rarely quoted in the literature, compared to the number of papers devoted to $\mathrm{N}$ in both $\mathrm{ZnO}$ as well as $\mathrm{SiC}$. One of the first SIMS result for the nitrogen measurement in $\mathrm{ZnO}$ was achieved using the $\mathrm{NCs}^{+}$ cluster [113]. In subsequent reports the SIMS measurement conditions were not given but certainly the $\mathrm{NO}^{-}$ cluster was used for nitrogen detection with reasonable detection limit $\left(10^{17} \mathrm{at} / \mathrm{cm}^{3}\right)[114,123,201]$. In case nitrogen detection in $\mathrm{SiC}$ by SIMS method, the literature is similarly poor as for $\mathrm{ZnO}$. Nevertheless, the SIMS measurement using $\mathrm{N}-{ }^{13} \mathrm{C}$ cluster was described in detail in [202]. By using high primary cesium beam current of $300 \mathrm{nA}$, rastered over the area $50 \times 50 \mu^{2}$, the record detection limit of $2 \times 10^{15}$ at $/ \mathrm{cm}^{3}$ was achieved. The dependence of primary beam current density on nitrogen detection limit based on $\mathrm{N}-{ }^{13} \mathrm{C}$ measurement was then characterized by the authors of [203].

In conclusion, nitrogen, despite the high ionization potential and low electron affinity, has one of the best detection limit for the atmospheric elements in semiconductors as measured by the SIMS method. This is a consequence of its strong bonds with the matrix elements such as $\mathrm{O}$ or $\mathrm{Si}$ and using the $\mathrm{N}-\mathrm{O}$ and $\mathrm{N}-\mathrm{Si}$ molecules as a detected species.

Table III lists the isotope RSF's for nitrogen as measured with CAMECA IMS6F using $\mathrm{Cs}^{+}$primary beam at the energy of $14.5 \mathrm{keV}$ in $\mathrm{ZnO}$ or $\mathrm{SiC}$.

\section{Oxygen}

Oxygen is the second abundant atmospheric element and constitutes over $20 \%$ of the Earth's atmosphere, and $\sim 46 \%$ of the Earth's crust. It is also the most reactive element present in the atmosphere, easily forming chemical compounds with the majority of elements. The high oxygen reactivity is due to its electron configuration. The two unpaired electrons of the $\mathrm{O}_{2}$ molecule make it highly susceptible to bond formation.

Oxygen occurs in two allotropic forms (oxygen $-\mathrm{O}_{2}$ and ozone $-\mathrm{O}_{3}$ ), both are excellent oxidants. Usually, oxygen is present in the oxidation state -2 in the $\mathrm{O}^{2-}$ form, but it can also form other ions, e.g., $\mathrm{O}_{2}^{2-}$ or $\mathrm{O}_{2}^{-}$. For various possible oxidation states, many molecular compounds can be formed.

In material engineering, oxygen is an issue mainly in III-V semiconductors, where in most cases act as a donor. A high oxygen content occurs in semiconductors containing elements very easily reacting with oxygen, i.e., $\mathrm{Al}$ in AlGaN and AlGaAs or Mn in MnGaAs and MnGaN.

\subsection{Oxygen properties in $G a N$}

Similarly to nitrogen in $\mathrm{ZnO}$, oxygen in GaN very easily substitutes the nitrogen site creating donor state $\mathrm{O}_{\mathrm{N}}$ being responsible for $n$-type conductivity in an undoped material. The first report on the growth of GaN crystals stated that the defects are responsible for the high electron conductivity of the material, mainly the nitrogen vacancy $\mathrm{V}_{\mathrm{N}}$. This hypothesis has been questioned by Seifert [204], pointing out the role of oxygen contamination. By removing oxygen from ammonia used for crystal epitaxy and using of $\mathrm{Mg}_{3} \mathrm{~N}_{2}$, significant reduction of electron concentration in GaN crystals was achieved. More comprehensive research on the oxygen in the GaN layers grown by the MOCVD method was performed by Chung and Gershenzon [205]. The increase of carrier concentration along with an increase of oxygen concentration was observed and the energy level of $\mathrm{O}_{\mathrm{N}}$ donor amounting to $78 \mathrm{meV}$ was determined by means of luminescence measurements. In the oxygen implanted GaN the ionization energy $(\sim 29 \mathrm{meV})$ of oxygen dopant was derived from electrical measurements [206]. From the redistribution of oxygen implanted into GaN, the upper limit of the oxygen diffusion coefficient at the level of $2.7 \times 10^{-13} \mathrm{~cm}^{2} / \mathrm{s}$ at the temperature of $1125^{\circ} \mathrm{C}$ was found. Low diffusion coefficient of oxygen was confirmed in $\mathrm{SiO}_{2} / \mathrm{GaN}$ samples [207]. The shallow donor state of oxygen dopant was suggested using the first principles calculation by authors of [208]. The formation energy of donor defect $\mathrm{O}_{\mathrm{N}}^{+}$is more than $2.5 \mathrm{eV}$ lower than nitrogen vacancy $\mathrm{V}_{\mathrm{N}}^{+}$, regardless of the Fermi level position in the band-gap. The same effect was observed in the AlN crystal. Similar results were obtained by Van de Walle [209]. Due to the high formation energy of nitrogen vacancy $V_{N}$, the defect is not formed during crystal growth, but only when its creation is forced by, for e.g., the ion implantation. At the same time, the low formation energy of substitutional oxygen $\mathrm{O}_{\mathrm{N}}$ and its high solubility in GaN was confirmed. Activation energy of $27 \mathrm{meV}$ was also determined on the basis of electrical measurements by the authors of [210], but formation energy of $\mathrm{O}_{\mathrm{N}}$ defect $(1.3 \mathrm{eV})$ was lower relative to previous theoretical calculations [208]. Several techniques were employed to study the properties of oxygen in GaN including infrared absorption [211] or photoluminescence [212]. Authors of [213-217] showed, that shallow oxygen donor state exists in $\mathrm{Al}_{x} \mathrm{Ga}_{1-x} \mathrm{~N}$ only for low $\mathrm{Al}$ content. For contents of $x>0.4$, the $\mathrm{O}_{\mathrm{N}}$ defect becomes a localized deep donor state, so-called DX center. Comprehensive calculations on the formation energy of oxygen-related defect in GaN using the density-functional theory, under various thermodynamic (high chemical potential $\mathrm{N}$ or $\mathrm{Ga}$ ) and electrical conditions (Fermi level) were performed by Wright [218]. The donor state of $\mathrm{O}_{\mathrm{N}}$ was confirmed and the double acceptor state of interstitial oxygen $\mathrm{O}_{\mathrm{I}}$ as well as the triple acceptor state of oxygen on gallium site $\mathrm{O}_{\mathrm{Ga}}$ was demonstrated (Fig. 10). For the high Fermi level and Ga-rich conditions the formation energy of all 3 defects are similar. For N-rich conditions, the formation energy 


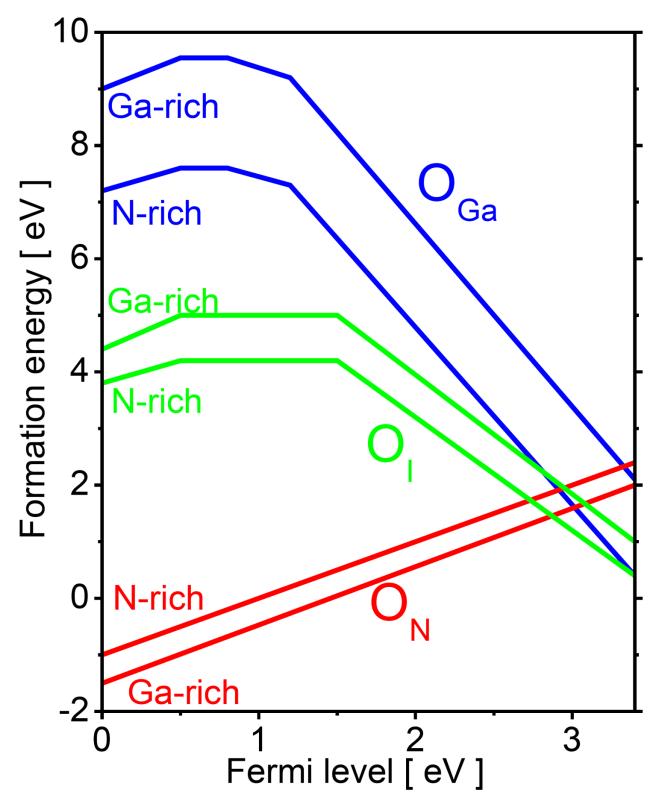

Fig. 10. Formation energies as a function of Fermi level for oxygen dopant in GaN under Ga-rich and N-rich conditions, as taken from ref. [218]. The zero of Fermi level corresponds to the top of the valence band.

of acceptor defects $\mathrm{O}_{\mathrm{I}}$ and $\mathrm{O}_{\mathrm{Ga}}$ is $2 \mathrm{eV}$ lower than that of donor defect $\mathrm{O}_{\mathrm{N}}$. In the $n$-type material at the high oxygen concentration, this may lead to compensation of the electron conductivity. For the Fermi level close to valence band $\mathrm{O}_{\mathrm{I}}$ and $\mathrm{O}_{\mathrm{Ga}}$ defects have high formation energy exceeding 4 and $7 \mathrm{eV}$ respectively. As a consequence, in GaN material, there is a small population of $\mathrm{O}_{\mathrm{Ga}}$ defects with respect to oxygen interstitials $\mathrm{O}_{\mathrm{I}}$ and gallium vacancy $\mathrm{V}_{\mathrm{Ga}}$. The author also drew attention to $\mathrm{Si}_{\mathrm{Ga}}$ donor and $\mathrm{Mg}_{\mathrm{Ga}}$ acceptor in complex with oxygen. In magnesium doped material the $\mathrm{O}_{\mathrm{N}}$ is the dominant donor defect that can compensate the hole conductivity. Moreover, the complex $\mathrm{Mg}_{\mathrm{Ga}}-\mathrm{O}_{\mathrm{N}}$ may exist in two configurations both with high dissociation energy making them possible to persist even at room temperature. The formation of such oxygen complexes was also confirmed by previous experimental results [25].

The oxygen concentration in GaN depends on the conditions of material growth [25]. MBE or MOCVD growth technology allows to obtain clean enough samples with oxygen concentration below the detection limit of the SIMS method $\left(<10^{16}\right.$ at $\left./ \mathrm{cm}^{3}\right)$. Equally low oxygen concentration is observed in crystals grown by halide vapor phase epitaxy (HVPE) [110, 219].

Bulk crystals growth methods such as high-pressure method [220], ammonothermal method [221] or increasingly popular $N a$-flux method, all suffer from insufficient crystal purity in terms of oxygen content [222, 223]. The best purity in this respect was found in $\mathrm{Na}$-flux method where the oxygen concentration has been reduced to a level of $\sim 3 \times 10^{16}$ at $/ \mathrm{cm}^{3}$. In the ammonothermal and high-pressure methods, these values exceed $10^{18}$ at $/ \mathrm{cm}^{3}$ and $10^{19}$ at $/ \mathrm{cm}^{3}$, respectively.
The first calculations based on the density functional theory showed [224], that oxygen is adsorbed more efficiently on the nitrogen side, whereby the crystal growth in the (000-1) direction produce a higher impurity concentration in the GaN layer. These results have been confirmed for both the MOCVD [225-228], as well as MBE [229] method. Higher oxygen concentration is also observed in crystal grown in non-polar and semipolar directions [230, 231]. The SIMS method was used to show [232] that in AlGaN layers more oxygen atoms incorporate into crystal under N-rich than Ga-rich conditions. In the crystal grown by $\mathrm{MBE}$ method the oxygen concentration decreases with increasing growth temperature what was confirmed in subsequent research [233, 234]. The specific oxygen content in GaN material is observable in the absorption or cathodoand photo-luminescence measurements, as well as by influence on the GaN thermal conductivity [235]. Annealing of the GaN:Mg layer under O-rich ambient atmosphere at the elevates temperatures efficiently reduces hydrogen in GaN material, causing the depassivation of $\mathrm{Mg}$ dopants and thus improving hole conductivity [236, 237]. At higher temperatures oxygen from the ambient atmosphere diffuse into the material and create compensating donors. Diffusion and incorporation of oxygen into the GaN layer occurs when the material growth is carried out on the oxygen contaminated substrate surface or substrate containing chemically unbounded oxygen atoms [238]. Unbound oxygen can diffuse into the defective material near the $\mathrm{GaN} / \mathrm{Al} 2 \mathrm{O} 3$ interface, changing its electrical properties [239]. However, the oxygen redistribution in $\mathrm{O}$ implanted $\mathrm{GaN}$ is not observed up to the temperature of $1200^{\circ} \mathrm{C}[238,240]$. Subsequent studies have shown that due to the high activation energy of oxygen diffusion in $\mathrm{GaN} \sim 3.9 \mathrm{eV}$, the incorporated oxygen atoms exhibits low mobility even at the temperatures close to the melting point of the material [241]. The implantation dose dependence may be of great importance for the position in the lattice as well as for oxygen mobility as demonstrated by Near Edge X-ray Absorption Fine Structure (NEXAFS) method [242]. For the low doses, $\sim 10^{15}$ at $/ \mathrm{cm}^{2}$ the oxygen atoms locate in the interstitial positions. When doses exceed $\sim 10^{16}$ at $/ \mathrm{cm}^{2}$ the oxygen atoms begin to occupy the nitrogen sites $\left(\mathrm{O}_{\mathrm{N}}\right.$ defect $)$ and becoming less mobile. At the dose of $\sim 10^{17} \mathrm{at} / \mathrm{cm}^{2}$ the $\mathrm{GaO}_{x} \mathrm{~N}_{y}$ phases are created.

Describing the defects induced by oxygen in the GaN lattice crystal, extended defects should be taken into account. The most popular substrate for GaN crystal growth is sapphire $\left(\mathrm{Al}_{2} \mathrm{O}_{3}\right)$, with a $13 \%$ lattice mismatch to the GaN lattice which leads to the formation of a large amount of dislocation $\left(\sim 10^{9} \mathrm{~cm}^{-2}\right)$. In the screw dislocations at a relaxed surface (10-10), the formation energy of $\mathrm{O}_{\mathrm{N}}$ defect is lower than at the stressed one [243]. It produces the oxygen segregation on the inner surface of the screw dislocation with possible attraction of gallium vacancy $\mathrm{V}_{\mathrm{Ga}}$ to form the complex defect $\mathrm{V}_{\mathrm{Ga}}-\left(\mathrm{O}_{\mathrm{N}}\right)_{3}$. According to the authors' calculations, such a surface 
defect is more stable by $2.2 \mathrm{eV}$ than a similar bulk defect. Oxygen segregation at such defect reaches the maximum concentration at the crystal surface, producing additional defect states in the band [244]. A combination of electron energy loss spectroscopy and atomic resolution imaging in the scanning transmission electron microscopy was used to show that the surface of dislocation possess up to 2 monolayers of nitrogen substituted by oxygen [245].

The high oxygen reactivity influeces various properties of semiconducting materials. One example is behavior of $\mathrm{Mn}$ and $\mathrm{Fe}$ in diluted magnetic semiconductors. The growth of such materials even using low residual gas methods as MOCVD or MBE can lead to excess oxygen incorporation in the $\mathrm{Fe}$ [246] or Mn [247] containing layers. The residual oxygen may produce the subsurface Mn depletion in the (Ga, Mn)N exposed to the ambient [248]. Most likely the segregation proceeds through surface reaction of both elements causing the outdiffusion of $\mathrm{Mn}$ from the subsurface layer of the material.

In summary, most studies point to the undesirable effects caused by the presence of oxygen in gallium nitride, such as generation of donor carriers, passivation of acceptor dopants or incorporation into extended crystal defects. Thus, the exact knowledge of oxygen thermodynamic parameters in GaN will allow for such control of technological processes to avoid undesirable effects associated with the impurity.

\subsection{Oxygen properties in $\mathrm{SiC}$}

In contrast to gallium nitride, undoped silicon carbide grown by various method contains so low oxygen content that its concentration level can hardly be measured by any available method. This is due to the very low oxygen solubility in $\mathrm{SiC}<10^{15}$ at $/ \mathrm{cm}^{3}$ at the growth temperatures of this material $1000-1500^{\circ} \mathrm{C}$ [249]. Calculations from first principles indicate two different activation energies for the diffusion of interstitial oxygen in cubic $\mathrm{SiC}(0.7$ or $2.5 \mathrm{eV}$ ) depending on whether the oxygen diffuses bonded to one $\mathrm{C}$ and two $\mathrm{Si}$ atoms, or two $\mathrm{Si}$ and one $\mathrm{C}$ atoms. The low diffusion coefficient of long-range diffusion is a consequence of high activation energy associated with one of the interstitial oxygen positions. While oxygen does not create point defects, it often plays a key role to form extended defects. The influence of oxygen on the formation of bubbles on the $\mathrm{SiC} / \mathrm{Si}$ interface during the $\mathrm{SiC}$ on $\mathrm{Si}$ growth by carbonization was described in [250]. The defect concentration is proportional to the oxygen content in silicon over the range of 7 orders of magnitude. A lot of the literature is also devoted to the oxidation of silicon carbide for production SOI (semiconductor-on-insulator) structures currently used in silicon based electronics. The first experimental results regarding $\mathrm{SiC}$ oxidation was published in the 1950s [251-253]. On the base of these studies, the oxidation rates of $\mathrm{Si}$ and $\mathrm{SiC}$ were compared [254]. The differences in the oxidation of the $\mathrm{Si}$ - and $\mathrm{C}$ - side of the material were shown in subsequent experimental work $[255,256]$. The oxidation process of the C-side occurs with two different activation energies depending on the temperature: $1.24 \mathrm{eV}$ below the temperature of $1350^{\circ} \mathrm{C}$ and $2.7 \mathrm{eV}$ beyond. Such a dependence was not observed in the Si-side oxidation, where the activation energy was in the range of $2.3-3.1 \mathrm{eV}$. The authors claim that below the temperature of $1300^{\circ} \mathrm{C}$ the oxidation process is dominated by molecular oxygen, while above this temperature the diffusion of ionized atomic oxygen made a significant contribution. A possible explanation for the difference in the oxidation rate is the different population of defects on the Si- or C-side [257]. Different stability of the $\mathrm{Si}_{4} \mathrm{C}_{4-x} \mathrm{O}_{2}(x \leq 2)$ phase forming on the interface was indicated in [258]. Dependence of the doping type on oxidation rate of both crystal sides was demonstrated in [259]. For the $n$-type Si-side the activation energy of oxidation was $0.8 \mathrm{eV}$ lower than for the $p$-type. The authors also refer to the broad literature of electrical measurements of the $\mathrm{SiO} 2 / \mathrm{SiC}$ system. An interesting oxidation effect at the temperature of $1050{ }^{\circ} \mathrm{C}$ was outlined in [260]. Sample cooling under the atmosphere free of oxygen produced the conversion from the silicon surface to the carbon surface. The oxygen presence during cooling led to the loss of the carbon layer and return to the original surface configuration. Such behavior of the $\mathrm{SiC}$ surface was confirmed by the phase diagram presented in [261]. The increase of oxygen overpressure at the constant oxidation temperature, results in phase transitions of the material surface between the three areas: (i) the lowest oxygen pressure - the surface contains $\mathrm{Si}(\mathrm{g}), \mathrm{CO}(\mathrm{g})$ and $\mathrm{C}(\mathrm{s})$, (ii) moderate oxygen pressure - the surface contains $\mathrm{SiO}(\mathrm{g})$ and $\mathrm{CO}(\mathrm{g})$, and (iii) the high oxygen pressure - the surface contains $\mathrm{SiO}_{2}(\mathrm{~s})$ and $\mathrm{CO}(\mathrm{g})$. A detailed description of the oxide growth on the SiC crystal surface was presented by the authors of [262]. The $\mathrm{SiO}_{2}$ thickness was measured by means of ellipsometry during the surface oxidation at the temperature of $1100{ }^{\circ} \mathrm{C}$ and under the pressure in the range of $0.02-1 \mathrm{~atm}$. At the low pressure, the growth rate of the initial oxide is very high and decreases until the $\mathrm{SiO}_{2}$ thickness reaches $7 \mathrm{~nm}$. Then the growth rate is stabilized at a higher level depending on the oxygen partial pressure.

An alternative method to fabricate an oxidized insulating layer is the oxygen implantation into $\mathrm{SiC}[263,264]$. Subsequent research showed $[265,266]$, that at the oxygen energy of $180 \mathrm{keV}$, the amorphous layer is formed only when the dose exceeds $4 \times 10^{17}$ at $/ \mathrm{cm}^{2}$. It confirms a high resistance of the $\mathrm{SiC}$ material to radiation damage. The oxidation of the layer grown by MOCVD and the $\mathrm{CH}_{n}^{+}$implanted silicon substrate was compared in [267]. Below oxygen content equal to $15 \%$ at the silicon oxide compound was not observed. Above this value a rapid separation of the $2 p$ silicon orbital was identified and the presence of oxygen compounds was accompanied by free carbon atoms.

The oxide layer may also be produced deep beneath the material surface by large radiation damage caused, 
e.g., by hydrogen implantation and annealing. Such effect was reported in $[58,63]$. The oxygen most likely penetrates from the ambient atmosphere by migrating from the sample edges along the heavily damaged and partially porous zone produced by hydrogen implantation.

\subsection{SIMS measurement of oxygen}

Oxygen, like other atmospheric elements, exhibits electronegative properties with large electron affinity $(\sim 1.5 \mathrm{eV})$ and very high ionization energy $(>13.6 \mathrm{eV})$. For this reason, in all materials measured by SIMS method, the highest ion yield of atomic oxygen is obtained with cesium primary beam and negative ion detection. Unlike the previously described elements, for obvious reasons, SIMS measurements of oxygen implanted $\mathrm{GaN}$ or SiC can only be accomplished the cesium beam, applying two configurations:

1. $\mathrm{Cs}^{+}$beam at the energy of $5.5 \mathrm{keV}$, positive ions collected, primary beam current at $200 \mathrm{nA}$, sputtered area $R=200 \times 200 \mu \mathrm{m}^{2}$,

2. $\mathrm{Cs}^{+}$beam at the energy of $14.5 \mathrm{keV}$, negative ions collected, primary beam current at $200 \mathrm{nA}$, sputtered area $R=200 \times 200 \mu \mathrm{m}^{2}$,

Depth profiles of oxygen implanted into both GaN and $\mathrm{SiC}$ show differences in the ion yield of negative $\mathrm{O}^{-}$and positive $\mathrm{O}^{+}$ion. For the $\mathrm{GaN}$ and $\mathrm{SiC}$ the difference is 4 and 7 order of magnitude, respectively (Fig. 11). Relatively high SIMS signals can be observed for cluster ions of $\mathrm{O}-\mathrm{N}$ in $\mathrm{GaN}$ or $\mathrm{O}-\mathrm{Si}$ in $\mathrm{SiC}$, both for negative as well as positive secondary ions. However, the $\mathrm{O}-\mathrm{Si}$ $(M / q=44 \mathrm{amu})$ cluster is accompanied by the impassable background from overlapping by $\mathrm{Si}_{3}^{2-}$ molecule (42 $\leq M / q \leq 45 \mathrm{amu})$.

It is also worth noting that the oxygen adsorption from residual gases on the $\mathrm{SiC}$ surface is much higher than on GaN surface under the same measurement conditions. It results in a 10 times higher background signal for silicon carbide (compare Fig. 11a, b - blue)

High enough $\mathrm{OCs}^{+}$cluster signal allows to use them as a standardless calibration of oxygen content in GaN [268]. This is because of comparable $\mathrm{OCs}^{+}$and $\mathrm{NCs}^{+}$ion yield in gallium nitride.

So far the standard SIMS analysis allows reaching the oxygen detection limit at the level of $10^{17} \mathrm{at} / \mathrm{cm}^{3}$ [237] and (Fig. 12). Special procedures aiming at reducing the oxygen-containing species adsorbed at the surface together with application of high density of primary current make it possible to reduce the detection limit by an order of magnitude as demonstrated in our laboratory [211, 226, 228, 229, 269] and Fig. 3. Additional lowering of this parameter for the doping and diffusion studies can be achieved by using rare isotopes ${ }^{17} \mathrm{O}$ or ${ }^{18} \mathrm{O}$, e.g., for implantation process [206, 238], or by isotope enriching the oxygen precursors in epitaxial processes [207].
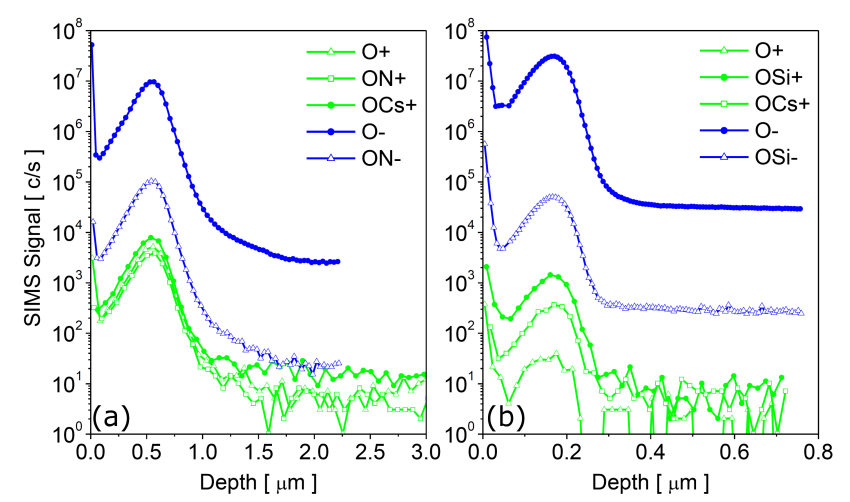

Fig. 11. Depth profiles of oxygen implanted into GaN or $\mathrm{SiC}$ materials, as measured under 2 different $(\mathrm{Cs}(+)$, Cs $(-))$ measurement condition: (a) $\mathrm{GaN}(D=1 \times$ $\left.10^{16} \mathrm{~cm}^{-2}, E=400 \mathrm{keV}\right),(\mathrm{b}) \mathrm{SiC}\left(D=5 \times 10^{15} \mathrm{~cm}^{-2}\right.$, $E=100 \mathrm{keV}$ ). The depth profiles of the ion signals with the highest ion yield at the same conditions are marked with the full symbols.
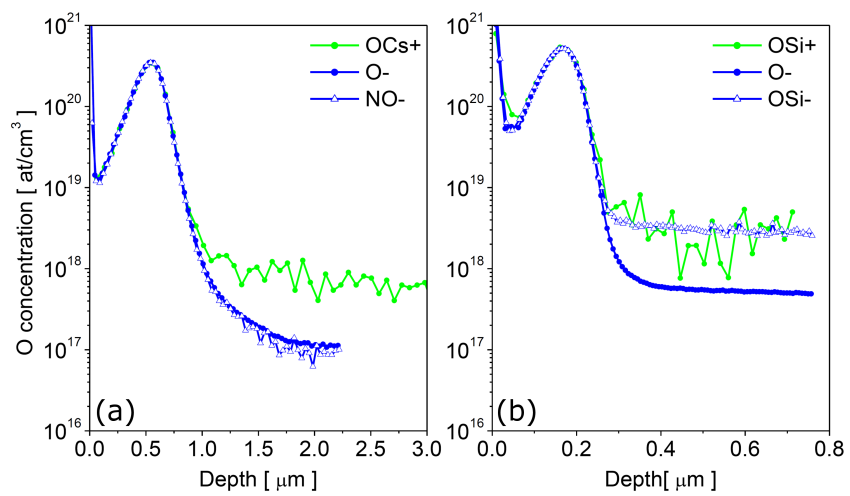

Fig. 12. Oxygen depth profiles in concentration scale as measured with $\mathrm{Cs}$ beam: (a) $\mathrm{GaN}(D=1 \times$ $\left.10^{16} \mathrm{~cm}^{-2}, E=400 \mathrm{keV}\right),(\mathrm{b}) \mathrm{SiC}\left(D=5 \times 10^{15} \mathrm{~cm}^{-2}\right.$, $E=100 \mathrm{keV})$.

TABLE IV

Isotope RSF's for oxygen as measured on CAMECA IMS $6 \mathrm{~F}, \mathrm{Cs}^{+}(14.5 \mathrm{keV})$, neg.

\begin{tabular}{c|c}
\hline \hline $\begin{array}{c}\text { O in GaN in reference to } \\
{ }^{69} \mathrm{Ga}^{-}\end{array}$ & $\begin{array}{c}\text { O in } \mathrm{SiC} \text { in reference to } \\
{ }^{30} \mathrm{Si}_{2}^{-}\end{array}$ \\
\hline${ }^{16} \mathrm{O}^{-} / 10^{19}$ & ${ }^{16} \mathrm{O}^{-} / 8 \times 10^{19}$
\end{tabular}

Table IV lists the isotope RSF's for oxygen as measured with CAMECA IMS6F using $\mathrm{Cs}^{+}$primary beam at the energy of $14.5 \mathrm{keV}$ in GaN or $\mathrm{SiC}$.

\section{References}

[1] C.G. Van de Walle, J. Neugebauer, Nature 423, 626 (2003).

[2] S. Nakamura, N. Iwasa, M. Senoh, T. Mukai, Jpn. J. Appl. Phys. 31, 1258 (1992).

[3] J.M. Zavada, R.G. Wilson, C.R. Abernathy, S.J. Pearton, Appl. Phys. Lett. 64, 2724 (1994). 
[4] M.S. Brandt, N.M. Johnson, R.J. Molnar, R. Singh, T.D. Moustakas, Appl. Phys. Lett. 64, 2264 (1994).

[5] J. Neugebauer, C.G. Van de Walle, Phys. Rev. Lett. 75, 4452 (1995).

[6] S.M. Myers, A.F. Wright, G.A. Petersen, W.R. Wampler, C.H. Seager, M.H. Crawford, J. Han, J. Appl. Phys. 89, 3195 (2001).

[7] S.M. Myers, A.F. Wright, J. Appl. Phys. 90, 5612 (2001).

[8] S.J. Pearton, R.G. Wilson, J.M. Zavada, J. Han, R.J. Shul, Appl. Phys. Lett. 73, 1877 (1998).

[9] A.Y. Polyakov, N. B. Smirnov, App. Phys. Lett. 79, 1834 (2001).

[10] B. Theys, Z. Teukam, F. Jomard, P. de Mierry, A.Y. Polyakov, M. Barbe, Semicond. Sci. Technol. 16, L53 (2001).

[11] R. Czernecki, E. Grzanka, R. Jakiela, S. Grzanka, C. Skierbiszewski, H. Turski, P. Perlin, T. Suski, K. Donimirski, M. Leszczynski, J. Alloys Compd. 747, 354 (2018)

[12] S.J. Pearton, H. Cho, F. Ren, J.-I. Chyi, J. Han, R.G. Wilson, MRS Online 595, F99W10.6 (1999).

[13] C.H. Seager, S.M. Myers, A.F. Wright, D.D. Koleske, A.A. Allerman, J. Appl. Phys. 92, 7246 (2002).

[14] A.F. Wright, C.H. Seager, S.M. Myers, D.D. Koleske, A.A. Allerman, J. Appl. Phys. 94, 2311 (2003).

[15] S. Limpijumnong, C.G. Van de Walle, Phys. Rev. B 68, 235203 (2003)

[16] Y. Kuwano, M. Kaga, T. Morita, K. Yamashita, K. Yagi, M. Iwaya, T. Takeuchi, S. Kamiyama, I. Akasaki, Jpn. J. Appl. Phys. 52, 08JK12 (2013).

[17] S. Nakamura, T. Mukai, M. Senoh, N. Iwasa, Jpn. J. Appl. Phys. 31, L139 (1992).

[18] C.H. Kuo, S.J. Chang, Y.K. Su, L.W. Wu, J.K. Sheu, C.Hs. Chen , G.C. Chi, Jpn. J. Appl. Phys. 41, L112 (2002).

[19] J. Yang, D. Zhaoa, D. Jiang, P. Chen, J. Zhu, Z. Liu, L. Le, X. He, X. Li, J. Vacum Sci. Technol. A 33, 021505 (2015).

[20] K. Orita, M. Kawaguchi, Y. Kawaguchi, S. Takigawa, D. Ueda, J. Electr. Mat. 38, 538 (2009).

[21] J. Neugebauer, C.G. Van de Walle, Appl. Phys. Lett. 68, 1829 (1996)

[22] A.F. Wright, Phys. Rev. B 60, 5101 (1999).

[23] S.M. Myers, A.F. Wright, G.A. Petersen, C.H. Seager, W.R. Wampler, M.H. Crawford, J.Han, J. Appl. Phys. 88, 4676 (2000).

[24] S.J. Pearton, C.R. Abernathy, C.B. Vartuli, J.W. Lee, J.D. MacKenzie, J. Vac. Sci. Technol A 14, 831 (1996).

[25] B. Clerjaud, D. Côtea, C. Nauda, R. BouananiRahbia, D. Wasik, K.Pakula, J.M. Baranowski, T. Suskic, E. Litwin-Staszewska, M. Bockowski, I. Grzegory, Physica B 308, 117 (2001).

[26] J.-P. Zhang, X.-L. Wang, D.-Z. Sun, M.-Y. Kong Semicond. Sci. Technol. 15, 619 (2000).

[27] E. Mollwo, Zeitschrift f'ur Physik, Bd. 138, 478 (1954).

[28] D.G. Thomas, J.J. Lander, J. Chem. Phys. 25, 1136 (1956).
[29] C.G. Van De Walle, Phys. Rev. Lett. 85(5), 1012 (2000).

[30] J. Bang, K.J. Chang, J. Korean Phys. Soc. 55(1), 98 (2009)

[31] M.D. McCluskey, S.J. Jokela, K.K. Zhuravlev, P.J. Simpson, K.G. Lynn, Appl. Phys. Lett. 81, 3807 (2002).

[32] S.J. Jokela, M.D. McCluskey, Phys. Rev. B 72, 113201 (2005)

[33] M.D. McCluskey, S.J. Jokela, W.M. Hlaing Oo, Physica B: Condensed Matter 376, 690 (2006).

[34] E.V. Lavrov, J. Weber, F. Borrnert, C.G. Van de Walle, R. Helbig, Phys. Rev. B 66, 165205 (2002).

[35] E.V. Lavrov, F. Börrnert, J. Weber, Phys. Rev. B 72, 085212 (2005)

[36] G.A. Shi, M. Stavola, S.J. Pearton, M. Thieme, E.V. Lavrov, J. Weber, Phys. Rev. B 72, 195211 (2005).

[37] E.V. Lavrov, F. Herklotz, J. Weber, Phys. Rev. Lett. 102, 185502 (2009)

[38] S.G. Koch, E.V. Lavrov, J. Weber, Phys. Rev. B 90 205212 (2014).

[39] R. Vidya, P. Ravindran, H. Fjellvag, arXiv:1309.5217v1, 2013.

[40] K. Ip, M.E. Overberg, Y.W. Heo, D.P. Norton, S.J. Pearton, S.O. Kucheyev, J.M. Zavada, Appl. Phys. Lett. 81(21), 3996 (2002).

[41] E.V. Monakhov, J.S. Christensen, K. Maknys, B.G. Svensson, A.Y. Kuznetsov, Appl. Phys. Lett. 87(19), 1 (2005).

[42] Z.Q. Chen, A. Kawasuso, Y. Xu, H. Naramoto, X.L. Yuan, T. Sekiguchi, T. Ohdaira, Phys. Rev. B 71(11), 115213 (2005)

[43] B. Theys, V. Sallet, F. Jomard, A. Lusson, J.-F. Rommeluére, Z. Teukam, J. Appl. Phys. 91, 3922 (2002).

[44] K. Ip, M.E. Overberg, Y.W. Heo, D.P. Norton, S.J. Pearton, C.E. Stutz, J.M. Zavada, Solid-State Electronics 47, 2255 (2003).

[45] M.S. Oh, D.K. Hwang, J.H. Lim, Y.S. Choi, S.J. Park, Appl. Phys. Lett. 91, 212102 (2007).

[46] W.J. Choyke, L. Patrick, Phys. Rev. Lett. 29, 355 (1972).

[47] L. Patrick, W.J. Choyke, Phys. Rev. B 8, 1660 (1973).

[48] M.A. Roberson, S.K. Estreicher, Phys. Rev. B 44, 10578 (1991).

[49] F. Gendron, L.M. Porter, C. Porte, E. Bringuier, Appl. Phys. Lett. 67, 1253 (1995).

[50] D.J. Larkin, S.G. Sridhara, R.P. Devanty, W.J. Choyke, J. Electron. Mater. 24(4), 289 (1995).

[51] J.M. Zavada, R.G. Wilson, F. Ren, S.J. Pearton, R.F. Davis, Solid-State Electronics 41, 677 (1997).

[52] N. Achtziger, J. Grillenberger, W. Witthuhn, M.K. Linnarsson, M. Janson, B. G. Svensson, Appl. Phys. Lett. 73, 945 (1998).

[53] M.K. Linnarsson, M. Janson, A. Sch'oner, N. Nordell, S. Karlsson, B.G. Svensson, Mater. Sci. Forum 264-268, 761 (1998). 
[54] N. Achtziger, C. Hulsen, W. Witthuhn, M.K. Linnarsson, M. Janson, B.G. Svensson, Phys. Status Solidi B 210, 395 (1998).

[55] M.S. Janson, A. Hallen, M.K. Linnarsson, B.G. Svensson, Phys. Rev. B 64, 195202 (2001).

[56] M.S. Janson, M.K. Linnarsson, A. Hallen, B.G. Svensson, N. Achtziger, L. Uneus, A. Lloyd Spetz, U. Forsberg, Phys. Scr. T108, 99 (2004).

[57] Y. Koshka, J.B. Dufrene, J.B. Casady, J. Electron. Mater. 32, 423 (2002).

[58] A. Barcz, M. Kozubal, R. Jakieła, J. Appl. Phys. 115, 223710 (2014).

[59] R. Jakieła, A. Barcz, Vacuum 70, 97 (2003).

[60] R. Jakieła, A. Barcz, E. Wegner, A. Zagojski, Vacuum 78, 417 (2005).

[61] R. Jakiela, A. Barcz, E. Dumiszewska, A. Jagoda, Phys. Status Solidi C 3, 1416 (2006).

[62] R. Jakieła, A. Barcz, E. Wegner, A. Zagojski, J. Alloys Compd. 423, 132 (2006).

[63] A. Barcz, R. Jakieła, M. Kozubal, J. Dyczewski, G.K. Celler, Nucl. Instrum. Methods Phys. Res. B 365, 146 (2015).

[64] M. Bruel, Electron. Lett. 31, 1201 (1995).

[65] G.K. Celler, S. Cristoloveanu, J. Appl. Phys. 93, 4955 (2003).

[66] R. Jakieła, A. Jasik, W. Strupiński, K. Góra, K. Kosiel, M. Wesołowski, Optica Applicata 32, 365 (2002).

[67] M. Kaminski, S. Podsiadlo, K. Wozniak, L. Dobrzycki, R. Jakiela, A. Barcz, M. Psoda, J. Mizera, J. Cryst. Growth 303, 395 (2007).

[68] R. Jakiela, A. Barcz, J. Sarnecki, G. K. Celler, oral presentation on SIMS 2017 conference in Kraków.

[69] M. Godlewski, E. Guziewicz, J. Szade, A. WójcikGłodowska, Ł. Wachnicki, T. Krajewski, K. Kopalko, R. Jakieła, S. Yatsunenko, E. Przeździecka, P. Kruszewski, N. Huby, G. Tallarida, S. Ferrari, Microelectron. Eng. 85, 2434 (2008).

[70] T.A. Krajewski, G. Łuka, Ł. Wachnicki, R. Jakieła, B. Witkowski, E. Guziewicz, M. Godlewski, N. Huby, G. Tallarida, Optica Applicata 39(4), 865 (2009).

[71] E. Guziewicz, M. Godlewski, L. Wachnicki, T.A. Krajewski, G. Luka, S. Gieraltowska, R. Jakiela, A. Stonert, W. Lisowski, M. Krawczyk, J.W. Sobczak, A. Jablonski, Semicond. Sci. Technol. 27, 074011 (2012).

[72] E. Kaminska, A. Piotrowska, J. Kossut, A. Barcz, R. Butkute, W. Dobrowolski, E. Dynowska, R. Jakiela, E. Przezdziecka, R. Lukasiewicz, M. Aleszkiewicz, P. Wojnar, E. Kowalczyk, Solid State Commun. 135, 11 (2005).

[73] E. Kaminska, I. Pasternak, P. Boguslawski, A. Jezierski, E. Dynowska, R. Jakiela, E. Przezdziecka, A. Piotrowska, J. Kossut, AIP Conf. Proc. 1199, 120 (2010).

[74] E. Guziewicz, M. I. Lukasiewicz, L. Wachnicki, K. Kopalko, A. Kovacs, R.E. Dunin-Borkowski, B.S. Witkowski, B.J. Kowalski, J. Sadowski, M. Sawicki, R. Jakiela, M. Godlewski, Radiat. Phys. Chem. 80, 1046 (2011).
[75] B.S. Witkowski, Ł. Wachnicki, R. Jakieła, E. Guziewicz, M. Godlewski, Acta Phys. Pol. A 120, A28 (2012).

[76] E. Kaminska, E. Przezdziecka, A. Piotrowska, J. Kossut, P. Boguslawski, I. Pasternak, R. Jakiela, E. Dynowska, Mater. Res. Soc. Symp. Proc. 957, 0957-K08-04 (2006).

[77] E. Przezdziecka, A. Wierzbicka, A. Reszka, K. Goscinski, A. Droba, R. Jakiela, D. Dobosz, T.A. Krajewski, K. Kopalko, J.M. Sajkowski, M. Stachowicz, M.A. Pietrzyk, A. Kozanecki, J. Phys. D: Appl. Phys. 46, 035101 (2013).

[78] G.M. Schott, C. Rüster, K. Brunner, C. Gould, G. Schmidt, L.W. Molenkamp, M. Sawicki, R. Jakiela, A. Barcz, G. Karczewski, Appl. Phys. Lett. 85, 4678 (2004).

[79] S. Fischer, C. Wetzel, E.E. Haller, B.K. Meyer, Appl. Phys. Lett. 67, 1298 (1995).

[80] P. Bogusławski, E.L. Briggs, J. Bernholc, Appl. Phys. Lett. 69, 233 (1996).

[81] H. Tang, J.B. Webb, J.A. Bardwell, S. Raymond, J. Salzman, C. Uzan-Saguy, Appl. Phys. Lett. 78, 757 (2001).

[82] J.B. Webb, H. Tang, S. Rolfe, J.A. Bardwel, Appl. Phys. Lett. 75, 953 (1999).

[83] M. Iwinska, R. Piotrzkowski, E. Litwin-Staszewska, T. Sochacki, M. Amilusik, M. Fijalkowski, B. Lucznik, M. Bockowski, Appl. Phys. Express 10, 011003 (2017).

[84] C.H. Seager, A.F. Wright, J. Yu, W. Gotz, J. Appl. Phys. 92, 6553 (2002).

[85] A.F. Wright, J. Appl. Phys. 92, 2575 (2002).

[86] L.E. Ramos, J. Furthmüller, J.R. Leite, L.M.R. Scolfaro, F. Bechstedt, Phys. status Solidi B 234(3), 864 (2002).

[87] J.L. Lyons, A. Janotti, C.G. Van de Walle, Appl. Phys. Lett. 97, 152108 (2010).

[88] T. Ogino, M. Aoki, Jpn. J. Appl. Phys. 19, 2395 (1980).

[89] A. Armstrong, A.R. Arehart, D.S. Green, U.K. Mishra, J.S. Speck, S.A. Ringel, J. Appl. Phys. 98, 053704 (2005).

[90] M. Matsubara, E. Bellotti, J. Appl. Phys. 121, 195701 (2017).

[91] M. Matsubara, E. Bellotti, J. Appl. Phys. 121 , 195702 (2017).

[92] A. Zado, E. Tschumak, J.W. Gerlach, K. Lischka, D.J. As, Journal of Crystal Growth 323, 88 (2011).

[93] X.G. He, D.G. Zhao, D.S. Jiang, Z.S. Liu, P. Chen, L.C. Le, J. Yang, X.J. Li, S.M. Zhang, J.J. Zhu, H.Wang, H. Yang, Thin Solid Films 564, 135 (2014).

[94] G. Piao, K. Ikenaga, Y. Yano, H. Tokunaga, A. Mishima, Y. Ban, T. Tabuchi, K. Matsumoto, J. Cryst. Growth 456, 137 (2016).

[95] F. Liang, D. Zhao, D. Jiang, Z. Liu, J. Zhu, P. Chen, J. Yang, W. Liu, X. Li, S. Liu, Y. Xing, L. Zhang, H. Yang, H. Long, M. Li, J. Cryst. Growth 467, 1 (2017).

[96] S. Limpijumnong, X. Li, S-H. Wei, S.B. Zhang, Appl. Phys. Lett. 86, 211910 (2005). 
[97] X. Li, S.E. Asher, S. Limpijumnong, S.B. Zhang, S.-H. Wei, T.M. Barnes, T.J. Coutts, R. Noufi, J. Sci. Technol. A: Vacuum, Surf., Films 24, 1213 (2006).

[98] H. Chen, S. Gu, W. Liu, S. Zhu, Y. Zheng, J. Appl. Phys. 104, 113511 (2008).

[99] S.T. Tan, X.W. Sun, Z.G. Yu, P. Wu, G.Q. Lo, D.L. Kwong, Appl. Phys. Lett. 91, 072101 (2007).

[100] Y.H. Lu, Z. X. Hong, Y.P. Feng, S.P. Russo, Appl. Phys. Lett. 96, 091914 (2010).

[101] L.T. Tseng, J.B. Yi, X.Y. Zhang, G.Z. Xing, H.M. Fan, T.S. Herng, X. Luo, M. Ionescu, J. Ding, S. Li, AIP Adv. 4, 067117 (2014).

[102] H. Pan, J.B. Yi, L. Shen, R.Q. Wu, J.H. Yang, J.Y. Lin, Y.P. Feng, J. Ding, L.H. Van, J.H. Yin, Phys. Rev. Lett. 99, 127201 (2007).

[103] T.S. Herng, S.P. Lau, L. Wang, B.C. Zhao, S.F. Yu, M. Tanemura, A. Akaike, K.S. Teng, Appl. Phys. Lett. 95, 012505 (2009).

[104] D.K. Mishra, J. Mohapatra, M.K. Sharma, R. Chattarjee, S.K. Singh, S. Varma, S.N. Behera, S.K. Nayak, P. Entel, J. Magn. Magn. Mater. 329, 146 (2013).

[105] C. Takakuwa-Hongo, M. Tomita, Surf. Interface Anal. 25, 966 (1997).

[106] S.E. Bradforth, E. Ha Kim, D.W. Arnold, D.M. Neumark, J. Chem. Phys. 98, 800 (1993).

[107] X. Li, Ö. Danielsson, H. Pedersen, E. Janzén, U. Forsberg, J. Vacuum Sci. Technol. B 33, 021208 (2015).

[108] M. Iwinska, T. Sochacki, M. Amilusik, P. Kempisty, B. Lucznik, M. Fijalkowski, E. Litwin-Staszewska, J. Smalc-Koziorowska, A. Khapuridze, G. Staszczak, I. Grzegory, M. Bockowski, J. Cryst. Growth 456, 91 (2016).

[109] M. Iwinska, M. Amilusik, M. Fijalkowski, T. Sochacki, B. Lucznik, E. Grzanka, E. LitwinStaszewska, J.L. Weyher, A. Nowakowska-Siwinska, G. Muziol, C. Skierbiszewski, I. Grzegory, E. Guiot, R. Caulmilone, M. Bockowski, J. Cryst. Growth 456, 73 (2016).

[110] M. Bockowski, M. Iwinska, M. Amilusik, M. Fijalkowski, B. Lucznik, T. Sochacki, Semicond. Sci. Technol. 31, 093002 (2016).

[111] P. Fuchs, J. Steinhauser, E. Avancini, Y.E. Romanyuk, A.N. Tiwar, RSC Adv. 6, 53768 (2016).

[112] A. Kobayashi, O.F. Sankey, J.D. Dow, Phys. Rev. B 28, 946 (1983).

[113] K. Iwata, P. Fons, A. Yamada, K. Matsubara, S. Niki, J. Cryst. Growth 209, 526 (2000).

[114] D.C. Look, D.C. Reynolds, C.W. Litton, R.L. Jones, D.B. Eason, G. Cantwell, Appl. Phys. Lett. 81, 1830 (2002).

[117] A.B.M.A. Ashrafi, I. Suemune, H. Kumano, S. Tanaka, Jpn. J. Appl. Phys. 41, L1281 (2002).

[118] S. Jiao, Y. Lu, Z. Zhang, B. Li, B. Yao, J. Zhang, D. Zhao, D. Shen, X. Fan, J. Appl. Phys. 102, 113509 (2007).

[119] H.W. Liang, Y.M. Lu, D.Z. Shen, Y.C. Liu, J.F. Yan, C.X. Shan, B.H. Li, Z.Z. Zhang, J.Y. Zhang, X.W. Fan, Phys. Status Solidi A 202(6), 1060 (2005).
[120] W.W. Liu, B. Yao, Z.Z. Zhang, Y.F. Li, B.H. Li, C.X. Shan, J.Y. Zhang, D.Z. Shen, X.W. Fan, J. Appl. Phys. 109, 093518 (2011).

[121] E. Przeździecka, M. Stachowicz, S. Chusnutdinow, R. Jakieła, A. Kozanecki, Appl. Phys. Lett. 106 062106 (2015).

[122] D. Snigurenko, K. Kopalko, T.A. Krajewski, R. Jakiela, E. Guziewicz, Semicond. Sci. Technol. 30, 015001 (2015)

[123] D. Snigurenko, E. Guziewicz, T.A. Krajewski, R. Jakiela, Y. Syryanyy, K. Kopalko, W. Paszkowicz, Mater. Res. Express 3, 125907 (2016).

[124] K. Minegishi, Y. Koiwai, K. Kikuchi, Jpn. J. Appl. Phys. 2(36), L1453 (1997).

[125] J.F. Rommeluere, L. Svob, F. Jomard, J. MimilaArroyo, A. Lusson, V. Sallet, Y. Marfaing, Appl. Phys. Lett. 83, 287 (2003).

[126] X. Li, Y. Yan, T.A. Gessert, C.L. Perkins, D. Young, C. DeHart, M. Young, T.J. Coutts, J. Vac. Sci. Technol. A 21, 1342 (2003).

[127] G. Du, Y. Ma, Y. Zhang, T. Yang, Appl. Phys. Lett. 87, 213103 (2005).

[128] C. Lin, S. Chen, S. Cheng, H. Lee, Appl. Phys. Lett. 84, 5040 (2004).

[129] X.D. Zhang, C.L. Liu, Z. Wang, Y.Y. Lu , L.J. Yin, Nucl. Instrum. Methods Phys. Res. B 254, 83 (2007).

[130] M.A. Myers, M.T. Myers, M.J. General, J.H. Lee, L. Shao, H. Wang, Appl. Phys. Lett. 101, 112101 (2012).

[131] X. Guo, H. Tabata, T. Kawai, J. Cryst. Growth 223 135 (2001).

[132] J.M. Bian, X.M. Li, C.Y. Zhang, W.D. Yu, X.D. Gao, Appl. Phys. Lett. 85, 4070 (2004).

[133] J. Lee, J. Ha, J. Hong, S. Cha, U. Paik, J. Vac. Sci. Technol. B 26(5) 1696 (2008).

[134] K. Shi, P.F. Zhang, H.Y. Wei, C.M. Jiao, P. Jin, X.L. Liu, S.Y. Yang, Q.S. Zhu, Z.G. Wang, J. Appl. Phys. 110, 113509 (2011).

[135] S. Dhara, P.K. Giri, Thin Solid Films 520, 5000 (2012).

[136] Y. Cao, L. Miao, S. Tanemura, M. Tanemura, Y. Kuno, Y. Hayashi, Appl. Phys. Lett. 88, 251116 (2006).

[137] B.S. Li, Y.C. Liu, Z.Z. Zhi, D.Z. Shen, Y.M. Lu, J.Y. Zhang, X.W. Fan, R.X. Mu, D.O. Henderson, J. Mater. Res. 18, 8 (2003).

[138] E. Kaminska, A. Piotrowska, J. Kossut, A. Barcz, R. Butkutec, W. Dobrowolski, E. Dynowska, R. Jakiela, E. Przezdziecka, R. Lukasiewicz, M. Aleszkiewicz, P. Wojnar, E. Kowalczyk, Solid State Commun. 135, 11 (2005).

[139] E. Kamińska, A. Piotrowska, J. Kossut, R. Butkutè, W. Dobrowolski, R. Łukasiewicz, A. Barcz, R. Jakieła, E. Dynowska, E. Przeździecka, M. Aleszkiewicz, P. Wojnar, E. Kowalczyk, Phys. Status Solidi C 2, 1119 (2005).

[140] E. Przeździecka, E. Kamińska, E. Dynowska, R. Butkutè, W. Dobrowolski, H. Kępa, R. Jakieła, M. Aleszkiewicz, E. Łusakowska, E. Janik, J. Kossut, Phys. Status Solidi C 2, 1218 (2005). 
[141] Z.Y. Xiao, Y.C. Liu, R. Mu, D.X. Zhao, J.Y. Zhang, Appl. Phys. Lett. 92, 052106 (2008).

[142] E.-C. Lee, Y.-S. Kim, Y.-G. Jin, K. J. Chang, Phys. Rev. B 64, 085120 (2001).

[143] Y. Yan, S.B. Zhang, S.T. Pantelides, Phys. Rev. Lett. 86(25), 5723 (2001).

[144] C.H. Park, S.B. Zhang, S.-H. Wei, Phys. Rev. B 66, 073202 (2002).

[145] L.G. Wang, A. Zunger, Phys. Rev. Lett. 90(25), 256401 (2003).

[146] Y. Marfaing, A. Lusson, Superlattices Microstruct. 38, 385 (2005).

[145] J.L. Lyons, A. Janotti, C.G. Van de Walle, Appl. Phys. Lett. 95, 252105 (2009).

[146] A. Boonchun, W.R.L. Lambrecht, Phys. Status Solidi B 250(10), 2091 (2013).

[147] N.Y. Garces, L. Wang, N.C. Giles, L.E. Halliburton, G. Cantwell, D.B. Eason, J. Appl. Phys. 94, 519 (2003).

[148] H.H. Woodbury, G.W. Ludwig, Phys. Rev. 124(4), 1083 (1961)

[149] L.J. Kroko, A.G. Milnes, Solid-State Electron. 9, 1125 (1966).

[150] E. Biedermann, Solid State Commun. 3, 343 (1965).

[151] G.B. Dubrovskii, A.A. Lepneva, E.I. Radovanova, Phys. Status Solidi B 57(1), 423 (1973).

[152] M. Ikeda, H. Matsunami, T. Tanaka, Phys. Rev. B 22(6), 2842 (1980).

[153] W. Suttrop, G. Pensl, W. J. Choyke, R. Stein S. Leibenzeder, J. Appl. Phys. 72, 3708 (1992).

[154] W. Götz, A. Schöner, G. Pensl, W. Suttrop, W.J. Choyke, R. Stein, S. Leibenzeder, J. Appl. Phys. 73, 3322 (1993).

[155] W.J. Moore, P.J. Lin-Chung, J.A. Freitas, Y.M. Altaiskii, V.L. Zuev, L.M. Ivanova, Phys. Rev. B 48(16) 12289 (1993).

[156] S.K. Lilov, Yu. N. Tairov, F. Tsvetkov, Kristall und Technik 14(1), 111 (1979).

[157] R.C. Glass, D. Henshall, V.F. Tsvetkov, C.H. Carter Jr., Phys. Status Solidi B 202, 149 (1997).

[158] N. Ohtani, M. Katsuno, J. Takahashi, H. Yashiro, M. Kanaya, J. Appl. Phys. 83, 4487 (1998).

[159] I.I. Parfenova, S.A. Reshanov, V.P. Rastegaev, Inorg. Mater. 38, 476 (2002).

[160] D.J. Larkin, P.G. Neudeck, J.A. Powell, L.G. Matus, Appl. Phys. Lett. 65, 1659 (1994).

[161] D.J. Larkin, Phys. Status Solidi B 202, 305 (1997).

[162] T. Kimoto, A. Itoh, H. Matsunami, Appl. Phys. Lett. 67, 2385 (1995).

[163] M. Bockstedte, A. Mattausch, O. Pankratov, Appl. Phys. Lett. 85, 58 (2004).

[164] A. Addamiano, G.W. Anderson, J. Comas, H.L. Hughes, W. Lucke, J. Electrochem. Soc. 119, 1355 (1972).

[165] S. Yaguchi T. Kimoto, N. Ohyama, H. Matsunami, Jpn. J. Appl. Phys. 34, 3036 (1995).

[166] T. Kimoto, N. Inoue, H. Matsunami, Phys. Status Solidi A 162, 263 (1997)
[167] R. Lossy, W. Reichert, E. Obermeier, W. Skorupa, J. Electron. Mater., 26(3), 123 (1997).

[168] G.J. Phelps, N.G. Wright, E.G. Chester, C.M. Johnson, A.G. O'Neill, S. Ortolland, A. Horsfall, K. Vassilevski, R.M. Gwilliam, P.G. Coleman, C.P. Burrows, Appl. Phys. Lett. 80, 228 (2002).

[169] S. Seshadri, G.W. Eldridge, A.K. Agarwal, Appl. Phys. Lett. 72, 2026 (1998)

[170] J. Gimbert, T. Billon, T. Ouisse, J. Grisolia, G. BenAssayag, C. Jaussaud, Mater. Sci. Eng. B61-62, 368 (1999).

[171] N.S. Saks, A.K. Agarwal, S.S. Mani, V.S. Hegde, Appl. Phys. Lett. 76, 1896 (2000).

[172] M. Laube, F. Schmid, G. Pensl, G. Wagner, M. Linnarsson, M. Maier, J. Appl. Phys. 92, 549 (2002).

[173] F. Li, Y. Sharma, V. Shah, M. Jennings, A. PérezTomás, M. Myronov, C. Fishera, D. Leadley, P. Mawby, Appl. Surf. Sci. 353, 958 (2015).

[174] M.A. Capano, J.A. Cooper, M.R. Melloch, A. Saxler, W.C. Mitchel, J. Appl. Phys. 87, 8773 (2000).

[175] R. B. Campbell, T.L. Chu, J. Electrochem. Soc. 113 825 (1966).

[176] S. Minagwa, H.C. Gatos, Jpn. J. Appl. Phys. 10(12), 1680 (1971).

[177] U. Forsberg, O. Danielsson, A. Henry, M.K. Linnarsson, E. Janzen, J. Cryst. Growth 236, 101 (2002).

[178] J. Meziere, P. Ferret, E. Blanquet, M. Pons, L. Di Cioccio, T. Billon, Mater. Sci. Forum 457-460, 731 (2004).

[179] G. Ferro, D. Chaussende, Sci. Rep. 7, 43069 (2017).

[180] S. Karmann, W. Suttrop, A. Schöner, M. Schadt C. Haberstroh, F. Engelbrecht, R. Helbig, G. Pensl, R.A. Stein, S. Leibenzeder, J. Appl. Phys. 72, 5437 (1992).

[181] J. Pernot, W. Zawadzki, S. Contreras, J.L. Robert, E. Neyret, L. Di Cioccio, J. Appl. Phys. 90, 1869 (2001).

[182] T. Kimoto, A. Itoh, H. Matsunami, S. Sridhara, L.L. Clemen, R.P. Devaty, W.J. Choyke, T. Dalibor, C. Peppermüller, G. Pensl, Appl. Phys. Lett. 67, $2833(1995)$

[183] H. Matsuura, T. Kimoto, H. Matsunami, Jpn. J. Appl. Phys. 38, 4013 (1999).

[184] G. Rutsch, R.P. Devaty, W.J. Choyke, D.W. Langer, L.B. Rowland, J. Appl. Phys. 842062 (1998).

[185] K. Racka-Dzietko, E. Tymicki, M. Raczkiewicz, K. Grasza, M. Kozubal, E. Jurkiewicz-Wegner, R. Jakieła, A. Brzozowski, M. Pawłowski, M. Piersa, J. Sadło, J. Krupka, Mater. Sci. Forum 615-617, 2733 (2009).

[186] K. Racka-Dzietko, E. Tymicki, K. Grasza, M. Raczkiewicz, R. Jakieła, M. Kozubal, E. Jurkiewicz-Wegner, A. Brzozowski, R. Diduszko, M. Piersa, K. Kościewicz, M. Pawłowski, J. Krupka, Mater. Sci. Forum 645-648, 21 (2010).

[187] E. Tymicki, K. Grasza, K. Racka, T. Łukasiewicz, M. Piersa, K. Kościewicz, D. Teklińska, R. Diduszko, P. Skupiński, R. Jakieła, J. Krupka, Mater. Sci. Forum 717-720, 29 (2012).

[188] T. Kimoto, Jpn. J. Appl. Phys. 54, 040103 (2015) 
[189] J. Berkowitz, W.A. Chupka, D. Gutman, J. Chem. Phys. 55, 2733 (1971).

[190] E.S. Chen, W.E. Wentworth, E.C.M. Chen, J. Mol. Struct. 606, 1 (2002).

[191] C.A. Arrington, T.H. Dunning Jr., D.E. Woon, J. Phys. Chem. A111, 11185 (2007).

[192] R. Jakieła, M. Trzyna, A. Barcz, 9th European Workshop on SIMS, SIMS Europe, Munster (Germany) 2014 - Poster 95.

[193] E. Kaminska, E. Przezdziecka, A. Piotrowska, J. Kossut, E. Dynowska, W. Dobrowolski, A. Barcz, R. Jakiela, E. Lusakowska, J. Ratajczak, Mater. Res. Soc. Symp. Proc. 891, 0891-EE08-11.1 (2006).

[194] E. Kaminska, A. Piotrowska, J. Kossut, R. Butkute, W. Dobrowolski, K. Golaszewska, A. Barcz, R. Jakiela, E. Dynowska, E. Przezdziecka, D. Wawer, Mater. Res. Soc. Symp. Proc. 786, E6.1 (2004).

[195] E. Kaminska, E. Przezdziecka, A. Piotrowska, J. Kossut, P. Boguslawski, I. Pasternak, R. Jakiela, E. Dynowska, Mater. Res. Soc. Symp. Proc. 957, 0957-K08-04 (2007).

[196] E. Przezdziecka, E. Kaminska, K.P. Korona, E. Dynowska, W. Dobrowolski, R. Jakieła, Ł. Kłopotowski, J. Kossut, Semicond. Sci. Technol. 22, 10 (2007).

[197] T.A. Krajewski, G. Luka, P.S. Smertenko, A.J. Zakrzewski, K. Dybko, R. Jakiela, L. Wachnicki, S. Gieraltowska, B.S. Witkowski, M. Godlewski, E. Guziewicz, Acta Phys. Pol. A 120, 17 (2011).

[198] K. Racka, E. Tymicki, K. Grasza, I.A. Kowalik, D. Arvanitis, M. Pisarek, K. Kościewicz, R. Jakieła, B. Surma, R. Diduszko, D. Teklińska, J. Mierczyk, J. Krupka, J. Cryst. Growth 377, 88 (2013).

[199] K. Racka, E. Tymicki, K. Grasza, R. Jakieła, M. Pisarek, B. Surma, A. Avdonin, P. Skupiński, J. Krupka, J. Cryst. Growth 401, 677 (2014).

[200] K. Racka, A. Avdonin, M. Sochacki, E. Tymicki, K. Grasza, R. Jakieła, B. Surma, W. Dobrowolski, J. Cryst. Growth 413, 86 (2015).

[201] K. Nakahara, H. Takasu, P. Fons, A. Yamada, K. Iwata, K. Matsubara, R. Hunger, S. Niki, Appl. Phys. Lett. 79, 4139 (2001).

[202] L. Wang, Mater. Sci. Forum 457, 771 (2004).

[203] H.E. Smith, K.G. Eyink, W.C. Mitchel, M.C. Wood, M.A. Fanton, Mater. Sci. Forum 527-529, 617 (2006).

[204] W. Seifert, R. Franzheld, E. Butter, H. Sobotta, V. Riede, Cryst. Res. Technol. 18, 383 (1983).

[205] B-C. Chung, M. Gershenzon, J. Appl. Phys. 72, 651 (1992).

[206] J.C. Zolper, R.G. Wilson, S.J. Pearton, R.A. Stall, Appl. Phys. Lett. 68, 1945 (1996).

[207] S.J. Pearton, H. Cho, J.R. LaRoche, F. Ren, R.G. Wilson, J.W. Lee, Appl. Phys. Lett. 75, 2939 (1999).

[208] T. Mattila, R.M. Nieminen, Phys. Rev. B 54, 16676 (1996).

[209] C.G. Van de Walle, C. Stampfl, J. Neugebauer, J. Cryst. Growth 189/190, 505 (1998).

[210] R.Y. Korotkov, B.W. Wessels, MRS Internet, J. Nitride Semicond. Res. 5, 301 (2000).
[211] W.J. Moore, J.A. Freitas, G.C.B. Braga, R.J. Molnar, S.K. Lee, K.Y. Lee, I.J. Song, Appl. Phys. Lett. 79, 2570 (2001)

[212] R. Niebuhr, K.H. Bachem, U. Kaufmann, M. Maier, C. Merz, B. Santic, P. Schlotter, J. Electron. Mater. 26, 1127 (1997).

[213] C. Wetzel, T. Suski, J.W. Ager III, E.R. Weber, E.E. Haller, S. Fischer, B.K. Meyer, R.J. Molnar, P. Perlin, Phys. Rev. Lett. 78, 3923 (1997).

[214] C.H. Park, D.J. Chadi, Phys. Rev. B 55, 12995 (1997).

[215] C.G. Van de Walle, Phys. Rev. B 57, R2033 (1998).

[216] C. Stampfl, C.G. Van de Walle, Appl. Phys. Lett. 72, 459 (1998).

[217] M.D. McCluskey, N.M. Johnson, C.G. Van de Walle, D.P. Bour, M. Kneissl, Phys. Rev. Lett. 80, 4008 (1998).

[218] A.F. Wright, J. Appl. Phys.98, 103531 (2005).

[219] R. Jakiela, A. Barcz, J. Sarnecki, G. K. Celler, "Ultrahigh Sensitivity SIMS Analysis of Oxygen in Silicon", oral presentation on SIMS 2017 conference in Kraków.

[220] J. Karpiński, J. Jun, S. Porowski, J. Cryst. Growth 66, 1 (1984).

[221] R. Dwiliński, R. Doradziński, J. Garczyński, L.P. Sierzputowski, A. Puchalski, Y. Kanbara, K. Yagi, H. Minakuchi, H. Hayashi, J. Cryst. Growth 311, 3015 (2009).

[222] Y. Mori, Y. Kitaoka, M. Imade, F. Kawamura, N. Miyoshi, M. Yoshimura, T. Sasaki, Phys. Status Solidi A 207, 1283 (2010).

[223] Y. Mori, Y. Kitaoka, M. Imade, N. Miyoshi, M. Yoshimura, T. Sasaki, J. Cryst. Growth 350, 72 (2012).

[224] T.K. Zywietz, J. Neugebauer, M. Scheffler, Appl. Phys. Lett. 74, 1695 (1999).

[225] M. Sumiya, K. Yoshimura, K. Ohtsuka, S. Fuke, Appl. Phys. Lett. 76, 2098 (2000).

[226] S. Heikman, S. Keller, S.P. DenBaars, U.K. Mishra, Phys. Status Solidi C 0, 2557 (2003).

[227] N.A. Fichtenbaum, T.E. Mates, S. Keller, S.P. DenBaars, U.K. Mishra, J. Cryst. Growth 310, 1124 (2008).

[228] S.C. Cruz, S. Keller, T.E. Mates, U.K. Mishra, S.P. DenBaars, J. Cryst. Growth 311, 3817 (2009).

[229] A.J. Ptak, L.J. Holbert, L. Ting, C. H. Swartz, M. Moldovan, N.C. Giles, T.H. Myers, Appl. Phys. Lett. 79, 2740 (2001).

[230] T. Paskowa, E.M. Goldys, R. Yakimova, E.B. Svedberg, A. Henry, B. Monemar, J. Cryst. Growth 208 , 18 (2000)

[231] J.L. Weyher, T. Sochacki, M. Amilusik, M. Fijałkowski, B. Łucznik, R. Jakieła, G. Staszczak, A. Nikolenko, V. Strelchuk, B. Sadovyi, M. Boćkowski, I. Grzegory, J. Cryst. Growth 403, 77 (2014).

[232] C.R. Elsass, T. Mates, B. Heying, C. Poblenz, P. Fini, P.M. Petroff, S.P. DenBaars, J.S. Speck, Appl. Phys. Lett. 77, 3167 (2000). 
[233] F. Schubert, S. Wirth, F. Zimmermann, J. Heitmann, T. Mikolajick, S. Schmult, Sci. Technol. Adv. Mater. 17, 239 (2016)

[234] S. Schmult, F. Schubert, S. Wirth, A. Großer, T. Mittmann, T. Mikolajick, J. Vacuum Sci. Technol. B 35, 02B104 (2017).

[235] G.A. Slack, L.J. Schowaltera, D. Morelli, J.A. Freitas Jr., J. Cryst. Growth 246, 287 (2002).

[236] R. Jakieła, A. Jasik, W. Strupiński, K. Góra, K. Kosiel, M. Wesołowski, Optica Applicata 32, 365 (2002).

[237] L.L. Wu, D.G. Zhao, D.S. Jiang, P. Chen, L.C. Le, L. Li, Z.S. Liu, S.M. Zhang, J.J. Zhu, H. Wang, B.S. Zhang, H. Yang, Semicond. Sci. Technol. 27, 085017 (2012).

[238] R. Jakieła, E. Dumiszewska, P. Caban, A. Stonert, A. Turos, A. Barcz, Phys. Status Solidi C 8, 1513 (2011).

[239] C. Mavroidis, J.J. Harris, M.J. Kappers, N. Sharma, C.J. Humphreys, E.J. Thrush, Appl. Phys. Lett. 79, 1121 (2001)

[240] Y. Nakano, T. Kachi, T. Jimbo, J. Vacuum Sci. Technol. B 21, 2602 (2003).

[241] B. Sadovyi, A. Nikolenko, J.L. Weyher, I. Grzegory, I. Dziecielewski, M. Sarzynski, V. Strelchuk, B. Tsykaniuk, O. Belyaev, I. Petrusha, V. Turkevich, V. Kapustianyk, M. Albrecht, S. Porowski, J. Cryst. Growth 449, 35 (2016).

[242] M. Katsikini, F. Boscherini, E.C. Paloura, Nucl. Instrum. Methods Phys. Res. B 268, 241 (2010).

[243] R. Jones, J. Elsner, M. Haugk, R. Gutierrez, Th. Frauenheim, M.I. Heggie, S. Öberg, P.R. Briddon, Phys. Status Solidi A 171, 167 (1999).

[244] I. Arslan, N. D. Browning, Phys. Rev. Lett. 91 , 165501 (2003).

[245] M.E. Hawkridge, D. Cherns, Appl. Phys. Lett. 87, 221903 (2005).

[246] A. Bonanni, M. Kiecana, C. Simbrunner, Ti. Li, M. Sawicki, M. Wegscheider, M. Quast, H. Przybylińska, A. Navarro-Quezada, R. Jakieła, A. Wolos, W. Jantsch, T. Dietl, Phys. Rev. B 75, 125210 (2007)

[247] K. Gas, J.Z. Domagala, R. Jakiela, G. Kunert, P. Dluzewski, E, Piskorska-Hommel, W. Paszkowicz, D. Sztenkiel, M.J. Winiarski, D. Kowalska, R. Szukiewicz, T. Baraniecki, A. Miszczuk, D. Hommel, M. Sawicki, J. Alloys Compd. 747, 946 (2018).
[248] R. Jakiela, K. Gas, M Sawicki, A. Barcz, J. Alloys Compd. 771, 215 (2019).

[249] M. Di Ventra, S.T. Pantelides, J. Electron. Mater. 29, 353 (2000).

[250] A. Leycuras, Appl. Phys. Lett. 70, 1533 (1997).

[251] T. Nakatogawa, J. Chem. Soc., Japan Ind. Chem. Sect. 57, 348 (1954).

[252] R.F. Adamsky, J. Phys. Chem. 63, 305 (1959).

[253] P.J. Jorgensen, M.E. Wadsworth, I.B. Cutler, J. Am. Ceram. Soc. 42, 613 (1959)

[254] K. Motzfeldt, Acta. Chem. Scand. 18, 1596 (1964).

[255] L. Muehlhoff, M.J. Bozack, W.J. Choyke, J.T. Yates, J. Appl. Phys. 60, 2558 (1986)

[256] Z. Zheng, R.E. Tressler, K.E. Spear, J. Electrochem. Soc. 137, 854 (1990)

[257] J.M. Powers, G.A. Somorjai, Surf. Sci. 244, 39 (1991).

[258] B. Hometz, H-J. Michel, J. Halbritter, J. Mater. Res. 9, 3088 (1994).

[259] A. Rys, N. Singh, M. Cameron, J. Electrochem. Soc. 142, 1318 (1995).

[260] P.E. Pehrsson, B.D. Thoms, J. Vac. Sci. Technol A 15, 1 (1997).

[261] Y. Song, F. W. Smith, Appl. Phys. Lett. 81, 3061 (2002).

[262] K. Kouda, Y. Hijikata, S. Yagi, H. Yaguchi, S. Yoshida, J. Appl. Phys. 112, 024502 (2012).

[263] W. Wesch, A. Heft, H. Hobert, G. Peiter, E. Wendler, T. Bachmann, Nuclear Instruments and Methods in Physics Research B 141, 160 (1998).

[264] N.P. Barradas, C. Jeynes, S.M. Jackson, Nucl. Instrum. Methods Phys. Res. B 136, 1168 (1998).

[265] M. Ishimaru, K.E. Sickafus, Appl. Phys. Lett. $\mathbf{7 5}$ 1392 (1999)

[266] M. Ishimaru, R.M. Dickerson, K.E. Sickafus, Appl. Phys. Lett. 75, 352 (1999).

[267] A. Avila, I. Montero, L. Galán, J.M. Ripalda, R. Levy, J. Appl. Phys. 89, 212 (2001).

[268] M. Hashiguchi, I. Sakaguchi, Y. Adachi, N. Ohashi, Jpn. J. Appl. Phys. 55, 101001 (2016). 